\title{
On the magnetic polarizability tensor of US coinage
}

DOI:

10.1088/1361-6501/aa9cf2

\section{Document Version}

Accepted author manuscript

Link to publication record in Manchester Research Explorer

\section{Citation for published version (APA):}

Davidson, J. L., Abdel-Rehim, O. A., Hu, P., Marsh, L. A., O'Toole, M. D., \& Peyton, A. J. (2018). On the magnetic polarizability tensor of US coinage. Measurement Science and Technology, 29(3), 035501.

https://doi.org/10.1088/1361-6501/aa9cf2

\section{Published in:}

Measurement Science and Technology

\section{Citing this paper}

Please note that where the full-text provided on Manchester Research Explorer is the Author Accepted Manuscript or Proof version this may differ from the final Published version. If citing, it is advised that you check and use the publisher's definitive version.

\section{General rights}

Copyright and moral rights for the publications made accessible in the Research Explorer are retained by the authors and/or other copyright owners and it is a condition of accessing publications that users recognise and abide by the legal requirements associated with these rights.

\section{Takedown policy}

If you believe that this document breaches copyright please refer to the University of Manchester's Takedown Procedures [http://man.ac.uk/04Y6Bo] or contact uml.scholarlycommunications@manchester.ac.uk providing relevant details, so we can investigate your claim.

\section{OPEN ACCESS}




\title{
On the Magnetic Polarizability Tensor of US Coinage
}

\author{
John L Davidson*, Omar A Abdel-Rehim, Peipei Hu, Liam A Marsh, \\ Michael D O'Toole and Anthony J Peyton
}

\author{
School of Electrical and Electronic Engineering, The University of Manchester, \\ Manchester, M13 9PL, United Kingdom
}

\begin{abstract}
The magnetic dipole polarizability tensor of a metallic object gives unique information about the size, shape and electromagnetic properties of the object. In this paper, we present a novel method of coin characterization based on the spectroscopic response of the absolute tensor. The experimental measurements are validated using a combination of tests with a small set of bespoke coin surrogates and simulated data. The method is applied to an uncirculated set of US coins. Measured and simulated spectroscopic tensor responses of the coins show significant differences between different coin denominations. The presented results are encouraging as they strongly demonstrate the ability to characterize coins using an absolute tensor approach.
\end{abstract}

Keywords: Magnetic Polarizability Tensor, Electromagnetic Induction Spectroscopy, Metal Detection, Landmine Discrimination, Coin

\section{Introduction}

The ability to accurately detect and characterize conducting objects from magnetic induction measurements is crucial in a wide range of applications. These include airport and port security, ensuring safety at public events, forensic and archeological surveys, quality control in large-scale food production, automated coin sorting and the detection of unexploded ordnance (UXOs) and land mines [1-6]. Additionally, there is an interest in conductivity imaging when using multiple magnetic induction measurements in magnetic induction tomography for medical imaging $[7,8]$ and industrial applications [9]. Moreover, eddy currents have important applications in non-destructive testing such as steel characterization $[10,11]$ and measuring the integrity of steel reinforcing bars within concrete structures $[12,13]$. In many of these application areas, the ability to distinguish targets of interest from background media and innocuous objects is of critical importance.

The magnetic dipole polarizability tensor ${ }^{\$}$ has been the focus of research and has proved successful in the characterization of large buried UXOs [14] as well as the classification of detected objects in an airport style walkthrough metal detector [15]. The tensor is an object specific property that depends on the shape, size, object's orientation and material composition. Coins are typical clutter items routinely found during humanitarian de-mining operations and security scans involving metal detectors. Therefore, a data library of coin tensors would be useful in these applications of metal detection.

Coin counterfeiting is an internationally widespread problem which has significant economic consequences. For example, in the United Kingdom, the incidence of one pound counterfeit coins has risen from approximately $1 \%$ to approximately $3 \%$ from 2004 to 2014 [16,17]. Such proportions equate to over ten million counterfeit one pound coins in circulation in the UK at any one time. Detailed examination of counterfeit coins is important for not only the discrimination from legal coins but also to determine the adopted manufacturing processes of illegal coins used by the counterfeiters. Forensic science examinations typically use combinations of microscopy and composition analysis by energy dispersive X-ray analysis, X-ray fluorescence and diffraction techniques $[18,19]$. However, application of these techniques to a single coin is time-consuming in both sample preparation and data interpretation.

In this paper we will present measured and simulated tensor data of an uncirculated 2014 set of US coins. Section 2 summarizes the main features of US coins and gives an overview of the tensor, describing its composition and basic properties. Sections 3 and 4 give details of the experimental and simulation methods used to acquire coin tensors and the associated eigenvalues. Section 5 presents repeatability and validation results using copper disk test pieces. The eigenvalues of the tensors of the US coin set is presented in section 6. Finally, section 7 concludes with a discussion on the potential of the tensor for coin classification and discrimination.

\section{Background}

\subsection{United States Mint and US Coinage}

The United States Mint is the sole manufacturer of legal tender coinage within the USA and is responsible for producing circulating coins necessary for supporting the nation's trade and commerce. At the time of writing, the current circulating coin denominations are: one-cent, 5-cent (or nickel), dime, quarter dollar, half dollar and dollar. The following sub-sections give brief descriptions of the features and manufacturing processes of US coinage derived from the relatively small amount of literature (for security reasons in order to limit counterfeiting) available in the public domain [e.g. 20 and 21].

Among the presently circulating US coins, the one-cent coin is plated and only the 5-cent coin is monolithic. All the remaining and higher value denominations are of a roll clad construction which is generally believed by US Mint engineers to provide greater security (to counterfeiting) compared with plated or monolithic coins. This is due to the clad layer providing a more consistent and well-defined electromagnetic signature measured in automated coin discriminators compared with that of a plated coin. The edges of coins are either plain, with reeds, or utilize edge lettering. The Native American coin and Presidential Dollar coins are physically the same size and are commonly referred to as the dollar. Table 1 describes the composition and dimensions of US coins.

\footnotetext{
* Corresponding Author

$\$$ For the sake of conciseness, the magnetic polarizability tensor will be referred to as simply the tensor within this paper.
} 
Table 1

Compositions and Dimensions of US Circulating Coins (adapted from [20] and [21]).

\begin{tabular}{|c|c|c|c|c|c|c|}
\hline Denomination & Cent & Nickel & Dime & Quarter Dollar & Half Dollar & Dollar \\
\hline Structure Type & $\begin{array}{c}\text { Copper } \\
\text { Plated Zinc }\end{array}$ & $\begin{array}{l}\text { Monolithic } \\
\text { Cupro-Nickel }\end{array}$ & $\begin{array}{l}\text { Cupro-Nickel } \\
\text { Clad Copper }\end{array}$ & $\begin{array}{l}\text { Cupro-Nickel } \\
\text { Clad Copper }\end{array}$ & $\begin{array}{l}\text { Cupro-Nickel } \\
\text { Clad Copper }\end{array}$ & $\begin{array}{c}\text { Manganese-Brass } \\
\text { Clad Copper }\end{array}$ \\
\hline $\begin{array}{l}\text { Bulk Composition }{ }^{1} \\
\text { (by weight) }\end{array}$ & $\begin{array}{c}2.5 \% \mathrm{Cu} \\
\text { Balance } \mathrm{Zn}\end{array}$ & $\begin{array}{c}25 \% \mathrm{Ni} \\
\text { Balance } \mathrm{Cu}\end{array}$ & $\begin{array}{c}8.33 \% \mathrm{Ni} \\
\text { Balance } \mathrm{Cu}\end{array}$ & $\begin{array}{c}8.33 \% \mathrm{Ni} \\
\text { Balance } \mathrm{Cu}\end{array}$ & $\begin{array}{c}8.33 \% \mathrm{Ni} \\
\text { Balance } \mathrm{Cu}\end{array}$ & $\begin{array}{c}6 \% \mathrm{Zn} \\
3.5 \% \mathrm{Mn} \\
2 \% \mathrm{Ni} \\
\text { Balance } \mathrm{Cu}\end{array}$ \\
\hline Core $^{2}$ & $\mathrm{~A} 190 \mathrm{Zn}$ & N/A & $\mathrm{C} 110 \mathrm{Cu}$ & $\mathrm{C} 110 \mathrm{Cu}$ & $\mathrm{C} 110 \mathrm{Cu}$ & $\mathrm{C} 110 \mathrm{Cu}$ \\
\hline Surface & $\begin{array}{c}8 \text { micron } \\
\text { Copper }\end{array}$ & N/A & $\begin{array}{l}0.175 \mathrm{~mm} \\
75 \mathrm{Cu}-25 \mathrm{Ni}\end{array}$ & $\begin{array}{l}0.226 \mathrm{~mm} \\
75 \mathrm{Cu}-25 \mathrm{Ni}\end{array}$ & $\begin{array}{l}0.289 \mathrm{~mm} \\
75 \mathrm{Cu}-25 \mathrm{Ni}\end{array}$ & $\begin{array}{c}0.413 \mathrm{~mm} \\
\text { Cu-12Zn-7Mn-4Ni }\end{array}$ \\
\hline Mass (g) & 2.500 & 5.000 & 2.268 & 5.670 & 11.340 & 8.100 \\
\hline Diameter $(\mathrm{mm})$ & 19.05 & 21.21 & 17.91 & 24.26 & 30.61 & 26.49 \\
\hline Thickness (mm) & 1.55 & 1.95 & 1.35 & 1.75 & 2.15 & 2.00 \\
\hline Edge Design & Plain & Plain & Reeds & Reeds & Reeds & Edge Lettering \\
\hline Number of Reeds & N/A & N/A & 118 & 119 & 150 & N/A \\
\hline
\end{tabular}

Notations and abbreviation: ${ }^{1} \mathrm{Cu}=$ Copper; $\mathrm{Mn}=$ Manganese; $\mathrm{Zn}=\mathrm{Zinc} ; \mathrm{Ni}=$ Nickel ${ }^{2} \mathrm{~N} / \mathrm{A}=$ Not Applicable

\subsection{The Tensor}

The response of the tensor is a function of frequency and depends on the target's shape, material properties and its orientation in relation to an applied primary magnetic field. Full mathematical descriptions of the tensor and, more generally, the perturbation of magnetic fields due to magnetic and conducting objects can be found in the pure and applied mathematics literature [22-25]. However, a more engineering approach to describing the tensor considers the representation of metallic responses as point dipoles. This approach has been used for object classification and has previously been presented in several publications for time and frequency domain systems [3, 26-29]. For conciseness, it is the intention of this paper to present only the key equations describing the tensor whilst complete derivations can be called upon from the provided references.

The response of a metallic object to an incident primary magnetic field can be represented by an induced magnetic dipole moment, $\overrightarrow{\boldsymbol{m}}$. The dipole approximation assumes that the primary field from an electromagnetic sensor is effectively parallel across the object. Compliance with this assumption has been shown to adequately represent the object's response for time and frequency domain systems [30]. The dipole approximation is presented in equation (1) and is defined in terms of the object's tensor, $\overleftrightarrow{\boldsymbol{M}}$, and the primary field, $\overrightarrow{\boldsymbol{H}}_{\boldsymbol{T}}$, provided by the electromagnetic sensor [1]:

$$
\overrightarrow{\boldsymbol{m}}=\overleftrightarrow{M} \cdot \vec{H}_{T}
$$

The induced voltage, $V_{\text {ind }}$, on the receive coil of the electromagnetic sensor can be represented in terms of the induced dipole moment as [29]:

$$
V_{\text {ind }} \approx \frac{j \omega \mu_{0}}{I_{R}} \overrightarrow{\boldsymbol{m}} \cdot \overrightarrow{\boldsymbol{H}}_{\boldsymbol{R}}
$$

where $\mu_{0}$ is the magnetic permeability of free space, $I_{R}$ is the current passing through the receive coil, $\vec{H}_{R}$ is the incident magnetic field on the receive coil and $\omega$ is the frequency at which the magnetic field is varying. Substitution of equation (1) into equation (2) gives the expression for the induced voltage in terms of the object's tensor and the magnetic fields in the electromagnetic sensor:

$$
V_{\text {ind }} \approx \frac{j \omega \mu_{0}}{I_{R}}\left(\overleftrightarrow{\boldsymbol{M}} \cdot \overrightarrow{\boldsymbol{H}}_{\boldsymbol{T}}\right) \cdot \overrightarrow{\boldsymbol{H}}_{\boldsymbol{R}}
$$

where $\overrightarrow{\boldsymbol{H}}_{\boldsymbol{T}}$ and $\overrightarrow{\boldsymbol{H}}_{\boldsymbol{R}}$ are representative of the sensitivity of the electromagnetic sensor [31], which is only determined by the coil geometry arrangement and can be calculated by numerical methods.

The tensor itself is a complex and frequency-dependent quantity which is commonly expressed as a $3 \times 3$ matrix of the following structure:

$\overleftrightarrow{\boldsymbol{M}}(f)=\left[\begin{array}{lll}{M^{\prime}}_{x x}+j M^{\prime \prime}{ }_{x x} & M^{\prime}{ }_{x y}+j M^{\prime \prime}{ }_{x y} & M^{\prime}{ }_{x z}+j M^{\prime \prime}{ }_{x z} \\ M^{\prime}{ }_{x y}+j M^{\prime \prime}{ }_{x y} & M^{\prime}{ }_{y y}+j M^{\prime \prime}{ }_{y y} & M^{\prime}{ }_{y z}+j M^{\prime \prime}{ }_{y z} \\ M^{\prime}{ }_{x z}+j M^{\prime \prime}{ }_{x z} & M^{\prime}{ }_{y z}+j M^{\prime \prime}{ }_{y z} & M^{\prime}{ }_{z z}+j M^{\prime \prime}{ }_{z z}\end{array}\right]$

It can be noted from equation (4) that the tensor comprises of 18 values (9 real and 9 imaginary), however, due to reciprocity between the transmit and receive fields, the tensor is symmetric, and consequently only contains 12 independent values ( 6 real and 6 imaginary). The complex nature of the tensor yields the implicit frequency dependence. Additionally, the tensor is orientation dependent and, therefore, a change in the orientation of the object (e.g. coin) in relation to the applied primary field will result in a change in the tensor. This orientation effect is shown in Fig. 1. 


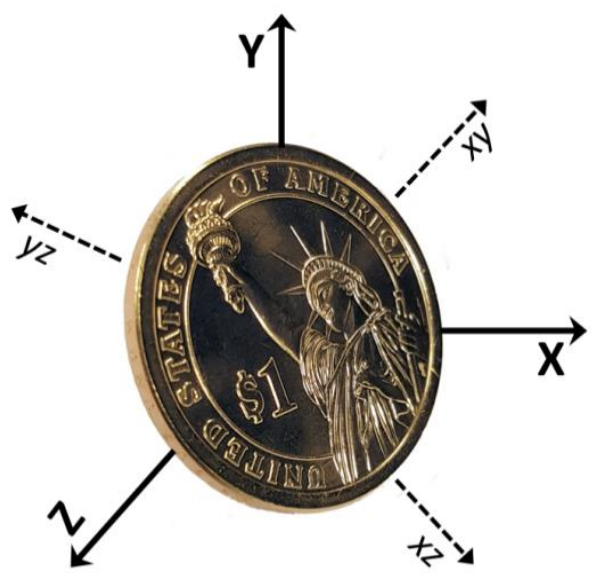

Fig. 1. Representation of the tensor components for a US one dollar coin in an arbitrary orientation.

The complex nature of the tensor relates to the conductive and magnetic characteristics of the object. For example, for a magnetic non-conducting object, all the tensor components are entirely real as the object concentrates the incident primary magnetic field along its axis. However, for a conductive, non-magnetic object, the incident primary field induces circulating eddy currents within the object which in turn produce a secondary magnetic field. This secondary field is represented in the complex components of the tensor. Similarly, for an object which is conductive and magnetic, e.g. ferritic steel, the tensor will also contains complex components. Fig. 2 shows examples of tensors for special case objects. A scalar multiple denoted by $k$, describes the magnitude of individual tensor components for the cases of; (a) a sphere, (b) a magnetic rod of negligible diameter with respect to length, (c) a non-magnetic disk of negligible thickness respect to diameter and (d) a magnetic disk of negligible thickness respect to diameter.

The inherent orientation dependence of the tensor described earlier in Fig. 1 may seem like a favourable property. However, in order to perform a meaningful (a)

Sphere

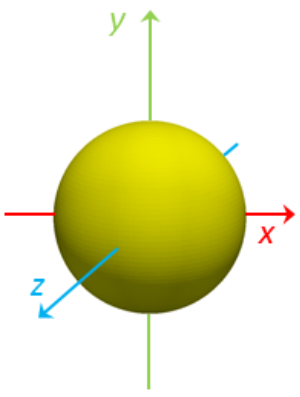

$$
\overleftrightarrow{\boldsymbol{M}}=\left[\begin{array}{ccc}
k_{1} & 0 & 0 \\
0 & k_{1} & 0 \\
0 & 0 & k_{1}
\end{array}\right]
$$

(b)

Magnetic Rod

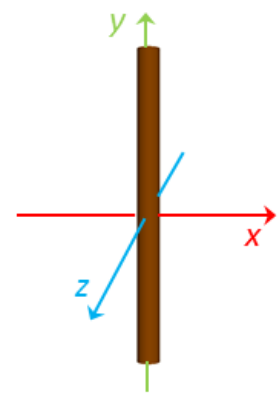

$\overleftrightarrow{\boldsymbol{M}}=\left[\begin{array}{ccc}0 & 0 & 0 \\ 0 & k_{2} & 0 \\ 0 & 0 & 0\end{array}\right]$ classification of a coin, orientation independence is required to ensure that some absolute metric can be attributed to the coin regardless of its orientation. In common with the classification methods used in buried UXO identification, anti-personnel landmine detection and airport security applications, this work uses the eigenvalue matrix, $\boldsymbol{\Lambda}$, of the tensor [e.g. 1, 3, 15, 32] for coin classification. In this way, the tensor of the coin can be represented by the eigenvalue matrix and a rotation matrix, $R$, to give an absolute measure of the tensor's frequency response characteristics. The rotation matrix is based on Euler's rotation theorem in an $x-y$ $z$ sequence as previously described [1] and relates the tensor to the eigenvalue matrix in the following way:

$$
\overleftrightarrow{\boldsymbol{M}}=R \cdot \boldsymbol{\Lambda} \cdot R^{T}
$$

where $\Lambda$ is the diagonal matrix:

$$
\boldsymbol{\Lambda}(f)=\left[\begin{array}{ccc}
\boldsymbol{\Lambda}_{x x}^{\prime}+j \boldsymbol{\Lambda}^{\prime \prime}{ }_{x x} & 0 & 0 \\
0 & \boldsymbol{\Lambda}_{y y}^{\prime}+j \boldsymbol{\Lambda}^{\prime \prime}{ }_{y y} & 0 \\
0 & 0 & \boldsymbol{\Lambda}_{z z}^{\prime}+j \boldsymbol{\Lambda}^{\prime \prime}{ }_{z z}
\end{array}\right]
$$

The spectroscopic and complex nature of tensor implicitly describes the phase shift exhibited between the applied primary field and the induced dipole or secondary field. This in turn depends on the electromagnetic properties of the object [30]. Consequently, the spectroscopic tensor can yield information about the object's material and size. For example, the real and imaginary tensor components represent the reactive and resistive responses of the object. The spectroscopic variation of these responses is inter-dependent with the object's shape, conductivity and permeability as described by Rehim et al. [32]. This makes the tensor a potentially useful tool for the identification of individual coin types and a discriminator from counterfeit coins. Additionally, in the case of a coin, due to two-axis symmetry only two unique eigenvalue orientations exist. Consequently, throughout this work, we subsequently refer to the general terminology of $\boldsymbol{\Lambda}_{x x}$ and $\boldsymbol{\Lambda}_{z z}$ simply as $\boldsymbol{\Lambda}_{l}$ and $\boldsymbol{\Lambda}_{3}$ (c)

Non-magnetic Disk

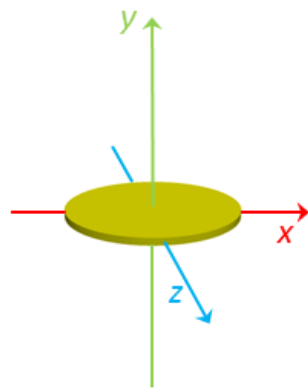

$\overleftrightarrow{\boldsymbol{M}}=\left[\begin{array}{ccc}0 & 0 & 0 \\ 0 & k_{3} & 0 \\ 0 & 0 & 0\end{array}\right]$ (d)

Magnetic Disk
Fig. 2. Example single frequency tensor components for the special case objects of a sphere, magnetic rod of negligible diameter, non-magnetic and magnetic disks of negligible thickness (adapted from [29]). For conciseness, the representation of the complex tensor is shown as a scalar multiple denoted by $k$ 


\section{Experimental Setup and Methods}

\subsection{System Overview}

The experimental setup is the same as used to derive the tensor for low metal anti-personnel mine surrogates as described elsewhere [32, 33]. A schematic of the measurement arrangement is shown in Fig. 3. The full system comprised of an impedance analyser (Solatron SI 1260), a bespoke coil for field generation and measurement, transmit (Tx) and receive (Rx) amplifiers, a high quality current sense resistor and a data acquisition PC. The impedance analyser used discrete fixed frequencies to excite the coil via amplification and measures trans-impedance values. In the present arrangement, the impedance analyser used frequencies in the range of $1 \mathrm{kHz}$ to $100 \mathrm{kHz}$ with 29 steps. The Tx amplifier (LT1210) enables the delivery of a suitable driving current (approximately $1.2 \mathrm{~A}$ ) to the excitation coil and the $\mathrm{Rx}$ amplifier (AD524) enlarges the induced voltage on the receive coil. Bespoke LabVIEW software controlled the impedance analyser and collected the measurement results from the system. The results are processed by a MATLAB program which performs data inversion and calculates the tensor. Validation of the system using a variety of welldefined test objects has been described by Rehim et al. [32].

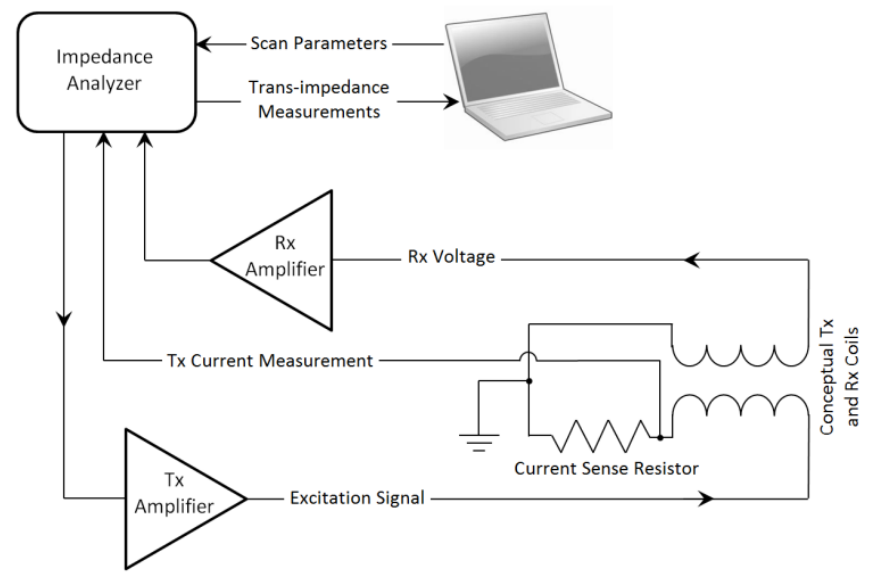

Fig. 3. System schematic showing signal flow along with measurements to and from the impedance analyser, front-end amplification and the sensing coils.

\subsection{Coil Arrangement and Coin Rotation Mechanism}

The coil arrangement comprised of a hollow cylindrical inner transmitter coil and two separated outer receiver coils, as shown in Fig. 4. The transmitter coil, visualised in red in Fig. 4(a), uses 120 wire turns, and the receiver coils comprise of 60 wire turns wound in reverse opposition. The coil dimensions are as follows; $a=202 \mathrm{~mm}, b=105 \mathrm{~mm}, \mathrm{H}=220$ $\mathrm{mm}, \mathrm{d}=107 \mathrm{~mm}$ and $\mathrm{D}=149 \mathrm{~mm}$. The $\mathrm{z}$-axis is defined as along the vertical length of the coils and passes through the centre of the coils. The passage of current in the transmitter coil generates an almost uniform magnetic field along this vertical symmetric axis of the coil. Inclusion of a target object (e.g. coin) positioned in the centre of the upper receive coil perturbs the impedances between the transmitter and two receiver coils which after amplification is measured with the impedance analyser.
A bespoke mechanical arrangement enabled the rotation of a single coin within the coils. The arrangement comprised of a 1:1 ratio rubber band driven pulley system of separated upper and lower pulley wheels. The lower pulley wheel was used to rotate the coin within the coils via the manual movement of the upper pulley wheel outside the coil arrangement. The coin was attached to the lower pulley wheel using reusable self-adhesive putty shown in Fig. 4(b). (a)

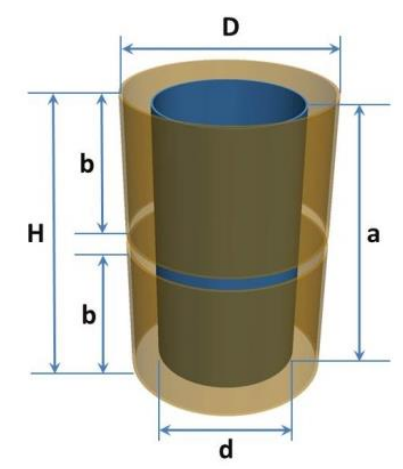

(b)

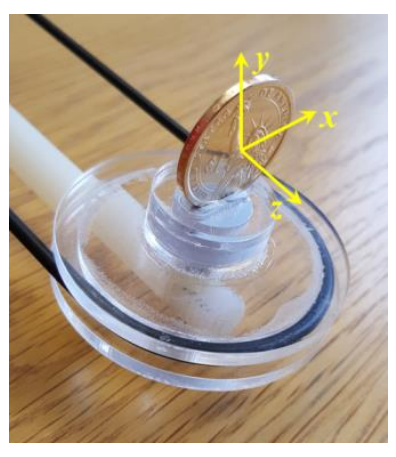

Fig. 4. Coil arrangement and coin rotation mechanism; (a) coils as used in FEM models and (b) close-up of coin rotation mechanism mounted with one dollar coin.

\subsection{Test Objects and Experimental Procedure}

Individual uncirculated coins and copper test disks were rotated about the y-axis in defined $15^{\circ}$ steps for a full $360^{\circ}$ rotation. At each angular rotation a full frequency sweep using the impedance analyser was performed from $1 \mathrm{kHz}$ to $100 \mathrm{kHz}$ in approximately logarithmic increments giving rise to 29 measured frequencies. The copper test disks were manufactured from copper rod to the dimensions of the dime, nickel, quarter and half dollar coins. The copper test disks and 5 of the measured coins are shown in Fig. 5.

Small phase shift errors introduced in the measurements by the front-end amplification were effectively cancelled out using a calibration of the system with a $6 \times 20 \mathrm{~mm}$ NiZn ferrite rod as described in [32]. A further calibration without any test object and using a Hall probe was used to measure $\overrightarrow{\boldsymbol{H}}_{\boldsymbol{T}}$ and $\overrightarrow{\boldsymbol{H}}_{\boldsymbol{R}}$ as described in [33]. This enabled the calculation of the tensor using bespoke MATLAB code by implementation of equation (3), and subsequently the eigenvalues $\Lambda(f)$ via equations (5) and (6).

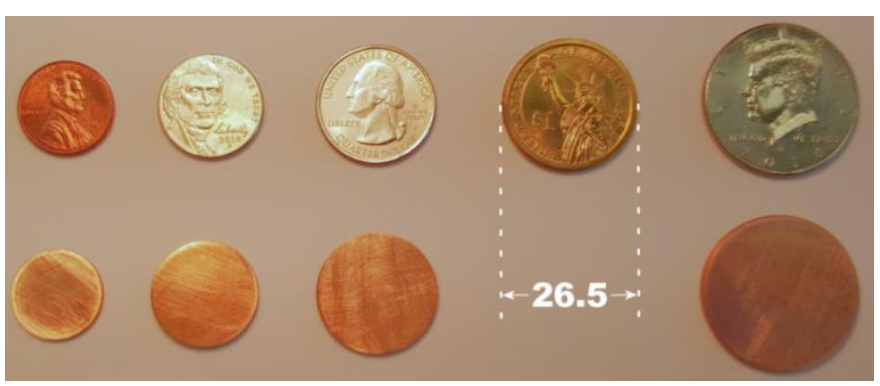

Fig. 5. Subset of US coins and copper disks used for tensor measurements. Scale in mm. Top row (left to right); cent, nickel, quarter dollar, dollar and half dollar. Bottom row; validation disks in the sizes of the dime, nickel, quarter dollar and half dollar. 


\section{Simulations}

Simulations were performed using the commercial FEM (Finite Element Method) solver, Ansys Maxwell v16. The simulation geometry comprised of an outer free-space region, the gradiometer arrangement as shown in Fig. 4(a) and the coin or copper disk positioned nominally at the most sensitive region of the coil arrangement. A series of 24 simulations involved geometrical rotations of each test object about its centre in $15^{\circ}$ increments from $0^{\circ}$ to $345^{\circ}$ over the frequency sweep range of $10 \mathrm{~Hz}$ to $100 \mathrm{MHz}$ in ten logarithmic increments per decade change giving rise to a total of 71 frequencies. Copper test disk models all used the conductivity for pure copper set at $5.8 \times 10^{7} \mathrm{~S} / \mathrm{m}$. Typical meshing involved a total of $150 \mathrm{k}$ tetrahedral elements per rotational model with between $8 \mathrm{k}$ to $15 \mathrm{k}$ elements per disk. Example $\mathrm{H}-$ field distributions of a dime-sized copper test disk in the gradiometer for a $100 \mathrm{kHz}$ excitation current at angular orientations of $0^{\circ}, 45^{\circ}$ and $90^{\circ}$ to the $\mathrm{z}$-axis is shown in Fig. 6 .

\subsection{Coin Modelling}

All coins were modelled to the dimensions as described in Table 1. Skin depth refinement was applied to the coins to increase the mesh density at the surface of the disks and correctly model the skin effects at high frequencies. The electrical conductivity of the metal and alloy content of the coins used values detailed in the review of binary alloy systems by Ho et al. [34].

The one-cent and nickel coins were modelled as simplistic solid monolithic disks. Two models of each of the one-cent and nickel coins were generated. The one-cent coin was firstly modelled using the electrical conductivity of pure zinc and secondly, modelled corresponding to $95 \%$ electrical conductivity of pure zinc. The nickel coin was firstly modelled using the electrical conductivity of 75-25 CuproNickel (CuNi) alloy and secondly, modelled corresponding to the electrical conductivity of 70-30 CuNi alloy.

The dime, quarter and half dollar coins were each modelled as disks with and without a top and bottom clad layer sandwiching a solid core. Where present, the clad layer respected the outermost dimensions of each coin type as described in Table 1. The cores of the dime, quarter and halfdollar coins were modelled corresponding to the electrical conductivity of 99-1 CuNi alloy. For those models which involved cladding, the clad layer was modelled corresponding to the electrical conductivity of 75-25 CuNi alloy.

Finally, 6 models of the one dollar coin were generated. All models used an inner core corresponding to the electrical conductivity of 99-1 CuNi alloy. Five models comprised of top and bottom clad layers sandwiching the core using electrical conductivity corresponding to $20 \%$ to $60 \%$ conductivity of pure copper in $10 \%$ incremental steps. The sixth model comprised of a complete wrap-around clad layer of the top, bottom and sides of the central core. This clad layer was set to an electrical conductivity corresponding to $30 \%$ conductivity of pure copper. As for the dime, quarter and half dollar, all clad layers respected the outermost dimensions of each coin type. Details of all the modelled coin parameters and set conductivities are given in Table 2. (a)

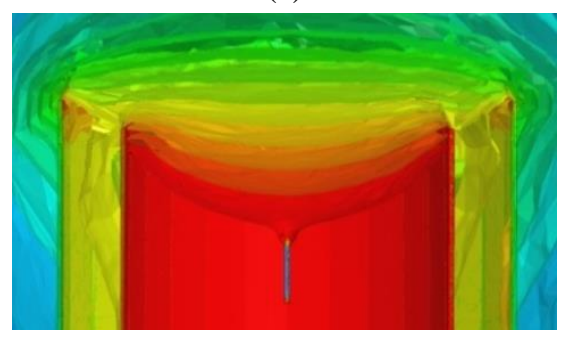

(b)

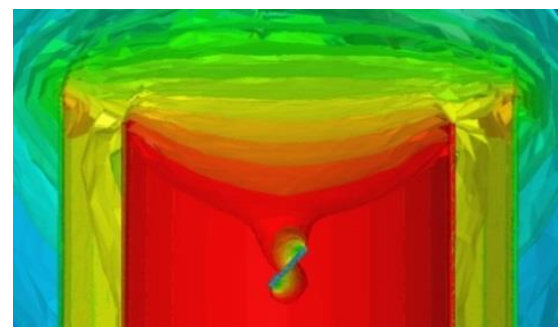

(c)

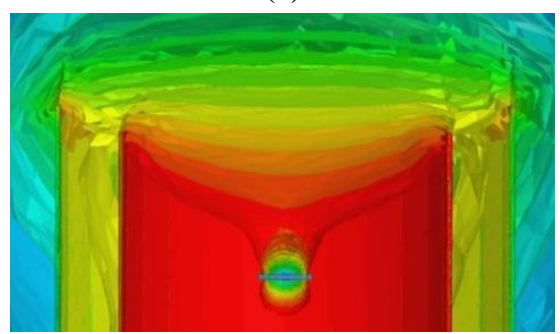

Fig. 6. Cross-sectional upper half of modelled gradiometer showing example $\mathrm{H}$ field perturbations due to the inclusion of a dime-sized copper disk; (a) at $0^{\circ}$, (b) $45^{\circ}$ and (c) $90^{\circ}$ to the z-axis. Midpoint of the disk is at the rotational centre and the most sensitive part of the gradiometer.

Table 2

Parameters and electrical conductivities $(\sigma)$ used for coin modelling. Conductivities are in S/m and derived from [34].

\begin{tabular}{|c|c|}
\hline & Model Details \\
\hline \multicolumn{2}{|l|}{ One Cent } \\
\hline Model 1 & modelled as pure Zinc $\left(\sigma=16.7 \times 10^{6}\right)$ \\
\hline Model 2 & modelled as $95 \%$ conductivity of Zinc $\left(\sigma=15.9 \times 10^{6}\right)$ \\
\hline \multicolumn{2}{|l|}{ Nickel } \\
\hline Model 1 & modelled as 75\%-25\% CuNi alloy $\left(\sigma=3.19 \times 10^{6}\right)$ \\
\hline Model 2 & modelled as $70 \%-30 \%$ CuNi alloy $\left(\sigma=2.72 \times 10^{6}\right)$ \\
\hline \multicolumn{2}{|l|}{ Dime and Quarter } \\
\hline Model 1 & modelled as $99 \%-1 \%$ CuNi alloy $\left(\sigma=35.1 \times 10^{6}\right)$ \\
\hline Model 2 & modelled as $99 \%-1 \%$ CuNi alloy core with $0.2 \mathrm{~mm}$ cladding of $75 \%-25 \%$ CuNi alloy $\left(\sigma=3.19 \times 10^{6}\right)$ \\
\hline \multicolumn{2}{|l|}{ Half Dollar } \\
\hline Model 1 & modelled as $99 \%-1 \%$ CuNi alloy $\left(\sigma=35.1 \times 10^{6}\right)$ \\
\hline Model 2 & modelled as $99 \%-1 \%$ CuNi alloy core with $0.3 \mathrm{~mm}$ cladding of $75 \%-25 \%$ CuNi alloy $\left(\sigma=3.19 \times 10^{6}\right)$ \\
\hline \multicolumn{2}{|l|}{ One Dollar } \\
\hline Models 1 to 5 & modelled as $99 \%-1 \%$ CuNi alloy core with $0.4 \mathrm{~mm}$ cladding of $20 \%$ to $60 \%$ Cu conductivity ${ }^{1}$ in $10 \%$ steps \\
\hline Model 6 & modelled as $99 \%-1 \%$ CuNi alloy core with $0.4 \mathrm{~mm}$ wrap-around cladding of $30 \%$ Cu conductivity \\
\hline
\end{tabular}

Notations: ${ }^{1}$ Conductivity of pure copper defined as $5.8 \times 10^{7} \mathrm{~S} / \mathrm{m}$ by the International Annealed Copper Standard (IACS). 
(a)

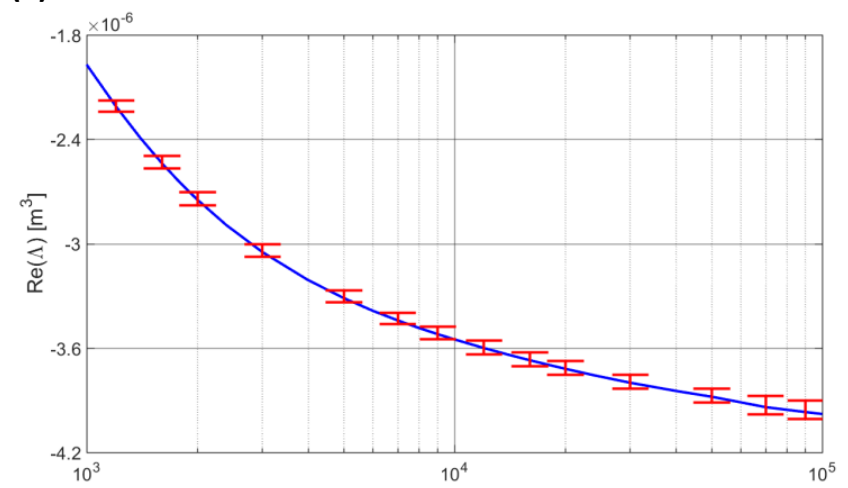

(c)

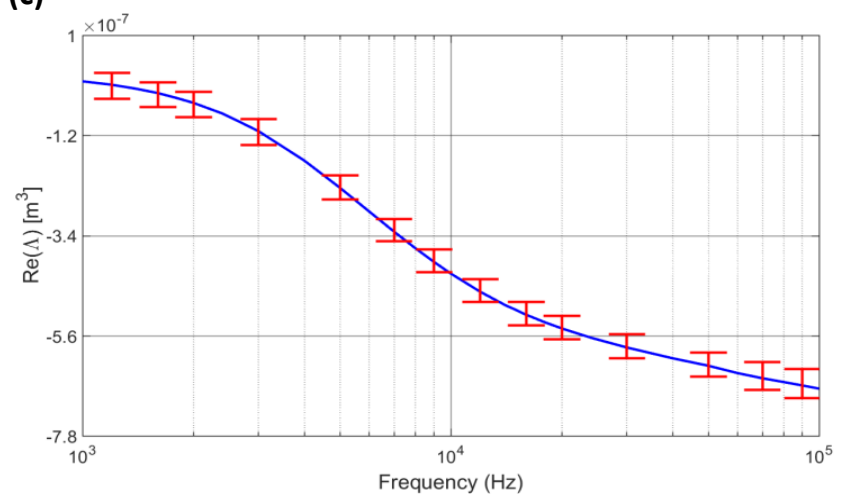

(b)

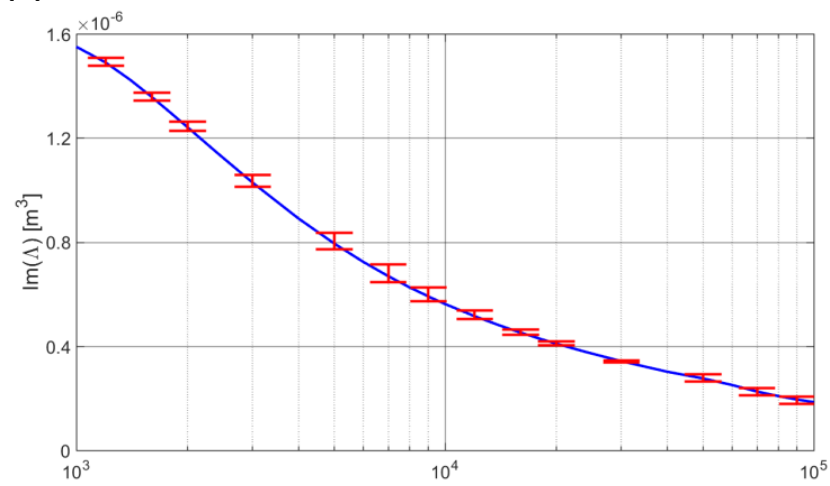

(d)

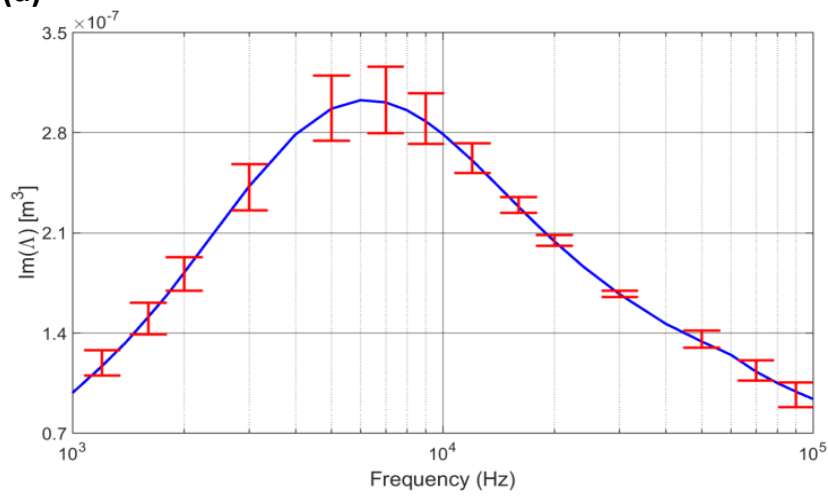

Fig. 7. Experimental real and imaginary eigenvalues of the derived magnetic polarizability tensor of the US nickel-sized copper disk. Solid line data are the mean of ten consecutive measurement acquisitions. Vertical bars show the minimum and maximum extent of the eigenvalues at alternate frequency values across the ten data acquisitions. Plots are for real (Re) and imaginary (Im) components of eigenvalue, $\Lambda_{1}$, in (a) and (b), whilst (c) and (d) show eigenvalue, $\Lambda_{3}$.

\subsection{Assessment of Simulation and Experimental Agreement}

The normalized RMS error, NRMSE was used to evaluate the level of agreement between the simulated and experimentally derived data across the frequency range used for the experimentally acquired data. The normalization refers to the mean of the simulated data interpolated to the 29 experimental frequencies, $n$. The NRMSE was calculated by bespoke MATLAB code using the formulae:

$$
N R M S E=\frac{\sqrt{\frac{\sum_{i=1}^{n}\left(E^{\left.2 x p t_{i}-S_{i}\right)_{i}}\right.}{n}}}{\overline{\operatorname{Sim}}}
$$

where $\operatorname{Expt}_{i}$ and $\operatorname{Sim}_{i}$ refer to the experimental and simulated data at the ith frequency and $\overline{S i m}$ is the average of the simulated data for the experimental frequency range. NRMSE values tending towards zero represent a high level of agreement between the experimental and the simulated data.

\section{System Repeatability and Testing with Copper Disks}

The system repeatability of experimentally derived eigenvalues of tensors was measured using a copper disk machined to the same size as the overall nominal dimensions of a US nickel. Full $360^{\circ}$ rotational and frequency data as described in section 3.3 were captured for ten separate acquisitions. The acquisitions were carried out within a period of 4 days. All measurements allowed for an instrumentation warm-up period of at least 2 hours. The shortest period between the end of one acquisition and the beginning of the next was in the order of 90 minutes. The longest period between two consecutive data acquisitions was in the order 14 hours. The nature of the timescales involved in consecutive data acquisition was deemed to be representative of both short and long term instrumentation stability. Additionally, these tests provided a first order indicator of any minor rotational errors introduced by the adopted manual coin rotation mechanism as typically used for acquisition of actual coin tensors. Fig. 7 shows the derived eigenvalues for the 10 consecutive data acquisitions associated with the US nickel-sized copper disk. The solid line is the mean of all acquisitions at each one of the acquired 29 spectroscopic frequencies. The vertical bars with horizontal end-caps show the maximum and minimum values of the eigenvalues across the 10 consecutive acquisitions at a given frequency. For clarity these bars are only plotted at alternate frequencies. The results show that the real component of eigenvalues, $\Lambda_{1}$ and $\Lambda_{3}$, are solely negative which is indicative of a conductive object. Additionally, an order of magnitude difference exists between $\Lambda_{1}$ and $\Lambda_{3}$ as a consequence of the first eigenvalue being indicative of the large cross-sectional obverse and reverse face area associated with the diameter of the disk and the second eigenvalue associated with the smaller cross-sectional area associated with the thickness of the disk.

Table 3

Range of the magnitude of standard deviation (SD) associated with the data presented in Fig. 7.

\begin{tabular}{lcccc}
\hline & \multicolumn{2}{c}{ eigenvalues, $\Lambda_{\mathbf{1}}$} & \multicolumn{2}{c}{ eigenvalues, $\Lambda_{\mathbf{3}}$} \\
& $\boldsymbol{R e}$ & $\boldsymbol{I m}$ & $\boldsymbol{R e}$ & $\boldsymbol{I m}$ \\
\hline SD range & $1.77-3.15$ & $0.25-1.86$ & $1.42-2.19$ & $0.14-1.57$ \\
$\left(\times \mathbf{1 0}^{-8} \mathbf{m}^{\mathbf{3}}\right)$ & & & & \\
\hline
\end{tabular}


(a)

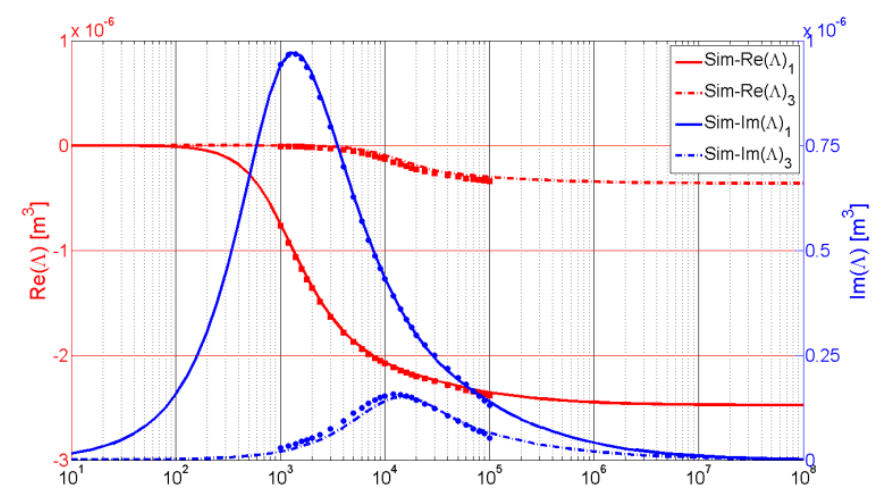

(c)

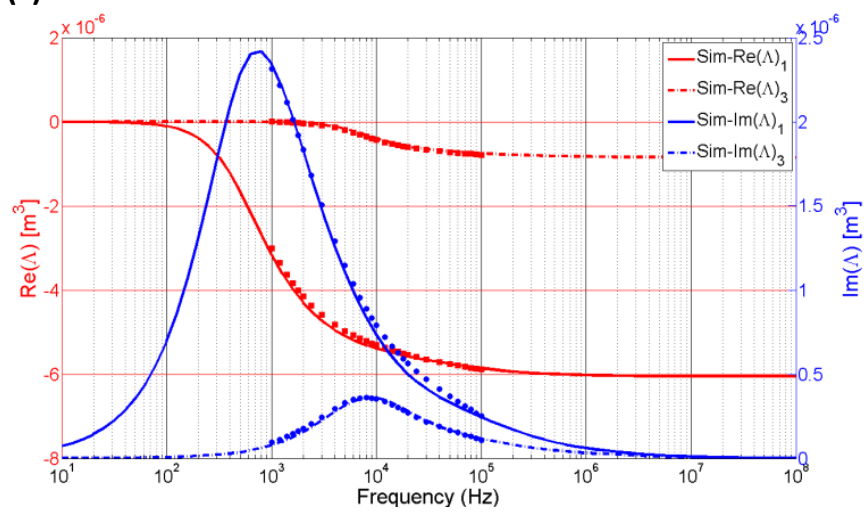

(b)

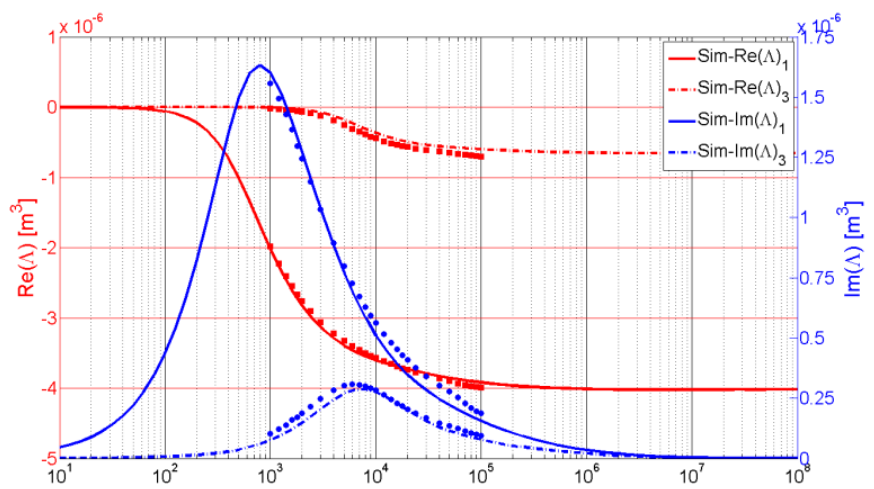

(d)

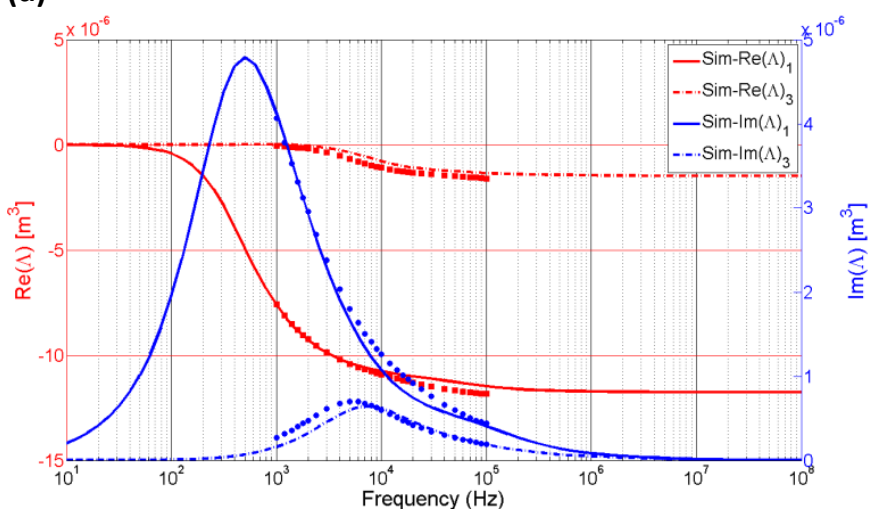

Fig. 8. Simulated and experimental real and imaginary eigenvalues of the derived magnetic polarizability tensors for copper disks machined to the US coin sizes of (a) dime, (b) nickel, (c) quarter dollar and (d) half dollar. Experimental data plotted as points. Simulated data shown as lines. Real and imaginary data are shown in red and blue respectively.

Table 4

NRMSE of the differences between simulated and experimental values for the copper disk data of Fig. 8.

\begin{tabular}{ccccc}
\hline & Real eigenvalues & \multicolumn{2}{c}{ Imaginary eigenvalues } & $\boldsymbol{\Lambda}_{\mathbf{1}}$ \\
\hline Cu Dime & $\mathbf{\Lambda}_{\mathbf{1}}$ & $\mathbf{\Lambda}_{\mathbf{3}}$ & 0.010 & 0.118 \\
Cu Nickel & 0.010 & 0.226 & 0.068 & 0.131 \\
Cu Quarter-Dollar & 0.014 & 0.172 & 0.043 & 0.059 \\
Cu Half-Dollar & 0.019 & 0.061 & 0.079 & 0.209 \\
\hline
\end{tabular}

The amount of variation for all eigenvalues for the repeatability testing is shown in Table 3 . The table gives the minimum and maximum values of the magnitude of standard deviations calculated at each of the 29 frequencies for the 10 measurement sets. Typically, the standard deviations are about two orders of magnitude different to absolute values in $\Lambda_{1}$ and better than one order of magnitude different to absolute values in $\Lambda_{3}$. Although great care was taken during data capture, such deviations can be considered to be acceptable since a dominant source of instability is likely to be as a consequence of any minor induced off-axis variation associated with the manual rotation on the copper disk.

Fig. 8 shows the data of derived tensor eigenvalues for the 4 copper disks shown in Fig. 5. All simulations used the definition of the IACS resistivity of copper as $17.241 \mathrm{n} \Omega \mathrm{m}$. The eigenvalues associated with the disks show good agreement between experimental and simulated data. For example, the dime-sized copper disk shown in Fig. 8(a) shows agreement between experimental and simulated peak magnitudes for the imaginary $\Lambda_{1}$ component better than $0.5 \%$ corresponding at the peak frequency of approximately 1.5 $\mathrm{kHz}$. The corresponding agreement at peak magnitudes for the imaginary $\Lambda_{3}$ component is approaching 5\%. This corresponds to a $12 \mathrm{kHz}$ peak in the experimental data.

Generally, for all disks, the eigenvalues of the tensors match relatively closely. This is particularly true for imaginary eigenvalue $\Lambda_{1}$ at frequencies up to about $30 \mathrm{kHz}$ beyond this the deviation between simulated and experimental data becomes more apparent. This deviation at higher frequencies is likely to be as a consequence of the induced eddy currents in the object being pushed to the outermost peripheral surface of the disk and hence at these frequencies the precise shape has more influence on the eddy current distribution, the skin depth and ultimately the imaginary component $\Lambda_{1}$. Table 4 shows the NRSME values as described by eq. (7) for the copper disks. The NRSME being relative to the mean in the experimental data gives an overall quantification of the goodness of fit between the simulated and experimental data. From the table, it can be seen that generally the greatest deviation occurs for eigenvalue $\Lambda_{3}$ irrespective of $\Lambda_{3}$ being real or imaginary. Despite this, the overall strong agreement between simulated and experimental data gives confidence in the adopted experimental procedure. The results are consistent with previous validation test exercises using the same experimental setup [32]. 
(a)

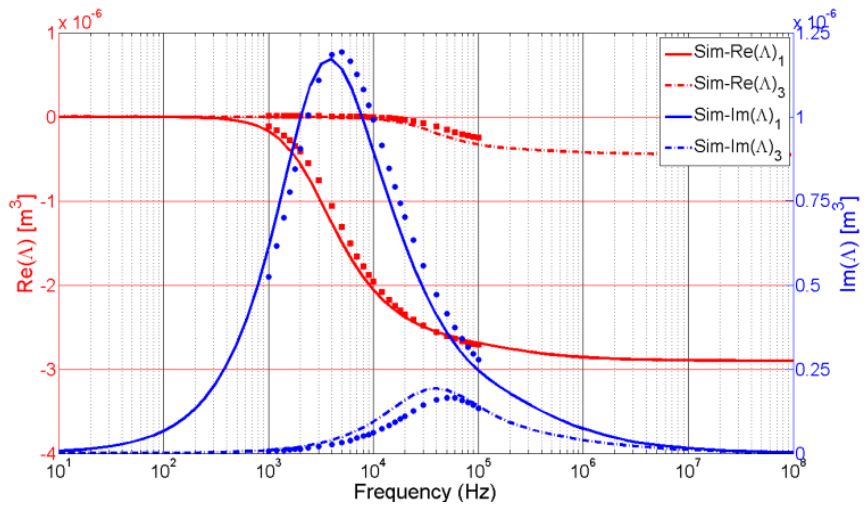

(b)

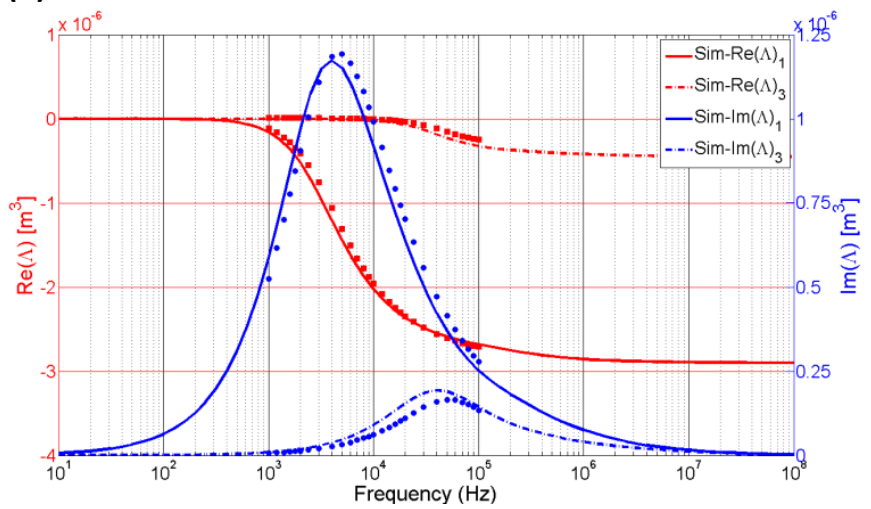

Fig. 9. US cent modelled as (a) pure Zinc $\left(16.7 \times 10^{6} \mathrm{~S} / \mathrm{m}\right)$ and (b) $95 \%$ Zinc conductivity $\left(15.9 \times 10^{6} \mathrm{~S} / \mathrm{m}\right)$

Table 5

NRMSE of the differences between simulated and experimental values for the US cent data of Fig. 9.

\begin{tabular}{|c|c|c|c|c|}
\hline & \multicolumn{2}{|c|}{ Real eigenvalues } & \multicolumn{2}{|c|}{ Imaginary eigenvalues } \\
\hline & $\Lambda_{1}$ & $\Lambda_{3}$ & $\Lambda_{1}$ & $\Lambda_{3}$ \\
\hline Pure Zinc & 0.060 & 0.548 & 0.102 & 0.263 \\
\hline 95\% Zinc & 0.044 & 0.518 & 0.078 & 0.245 \\
\hline
\end{tabular}

(a)

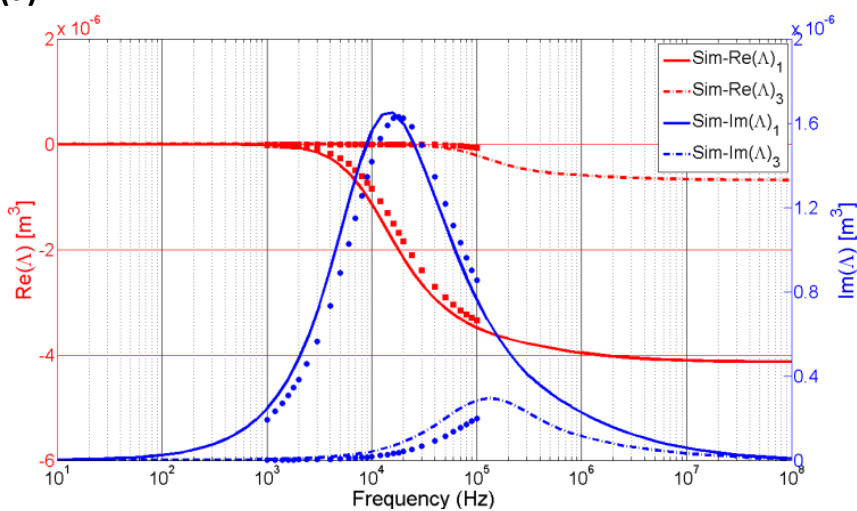

(b)

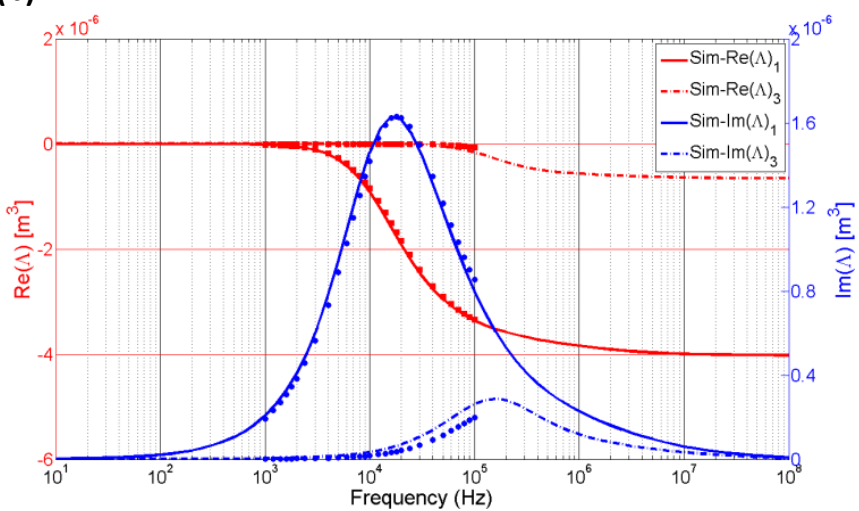

Fig. 10. US nickel modelled as (a) $75-25 \mathrm{CuNi}\left(3.19 \times 10^{6} \mathrm{~S} / \mathrm{m}\right)$ and (b) $70-30 \mathrm{CuNi}\left(2.72 \times 10^{6} \mathrm{~S} / \mathrm{m}\right)$

Table 6

NRMSE of the differences between simulated and experimental values for the US nickel data of Fig. 10.

\begin{tabular}{lcccc} 
& \multicolumn{2}{c}{ Real eigenvalues } & \multicolumn{2}{c}{ Imaginary eigenvalues } \\
& $\Lambda_{\mathbf{1}}$ & $\boldsymbol{\Lambda}_{\mathbf{3}}$ & $\boldsymbol{\Lambda}_{\mathbf{1}}$ & $\boldsymbol{\Lambda}_{\mathbf{3}}$ \\
\hline $\mathbf{7 5 - 2 5} \mathrm{CuNi}$ & 0.142 & 1.494 & 0.106 & 0.565 \\
$\mathbf{7 0 - 3 0} \mathbf{C u N i}$ & 0.038 & 1.330 & 0.035 & 0.444 \\
\hline
\end{tabular}

\section{Tensors of US Coins}

This section presents eigenvalues of the derived tensors for the US coins. As for the copper disk data, experimental eigenvalues are plotted as 29 discrete solid-filled markers over the frequency range of $1 \mathrm{kHz}$ to $100 \mathrm{kHz}$ whilst overlaid simulated eigenvalues are plotted over the frequency range from $10 \mathrm{~Hz}$ to $100 \mathrm{MHz}$. For all data, simulated eigenvalues $\Lambda_{1}$ and $\Lambda_{3}$ are shown as solid and broken lines respectively.

Fig. 9 shows the one cent experimental data compared with monolithic disk simulations set to conductivities of pure zinc and $95 \%$ conductivity of pure zinc. From Table 5, it can be seen that the better modelling agreement is for the model using $95 \%$ conductivity of pure zinc. This is particularly evident in the imaginary and real components of the larger eigenvalue, $\Lambda_{1}$, which suggests an overall improved fitting with the experimental data for the model using the lower conductivity of $15.9 \times 10^{6} \mathrm{~S} \mathrm{~m}^{-1}$ compared with the simulated data from the model considering pure zinc. In reality, the one cent comprises of a thin 8 micron copper plate layer over a solid zinc core. Such a thin layer is difficult to model using FEM with practicable computational time requirements. Despite this, the simplified monolithic tested models give reasonable agreements with experimental data considering the trade-off between absolute accuracy and computational effort.

Fig. 10 shows eigenvalue tensor data for the US nickel. From the experimental data, the peak frequency for the imaginary eigenvalue, $\Lambda_{1}$, is approximately $18 \mathrm{kHz}$. The position of this peak is heavily dependent on the coin's size and composition; for equal shape and sizes, the lower the conductivity the higher the peak frequency. For the US nickel, the $18 \mathrm{kHz}$ peak frequency is significantly higher compared with that of the case for the one cent coin which 
exhibits a peak frequency in the imaginary component eigenvalue, $\Lambda_{1}$, at approximately $5 \mathrm{kHz}$ as shown in Fig. 9. This is consistent with the significantly lower conductivity of the monolithic $\mathrm{CuNi}$ nickel coin compared with the higher conductivity one-cent coin which is primarily based on zinc. As for the case of the one cent, the simulated data for the US nickel gives reasonable agreement with experimentally derived eigenvalues. This is quantified in Table 6 which

(a)

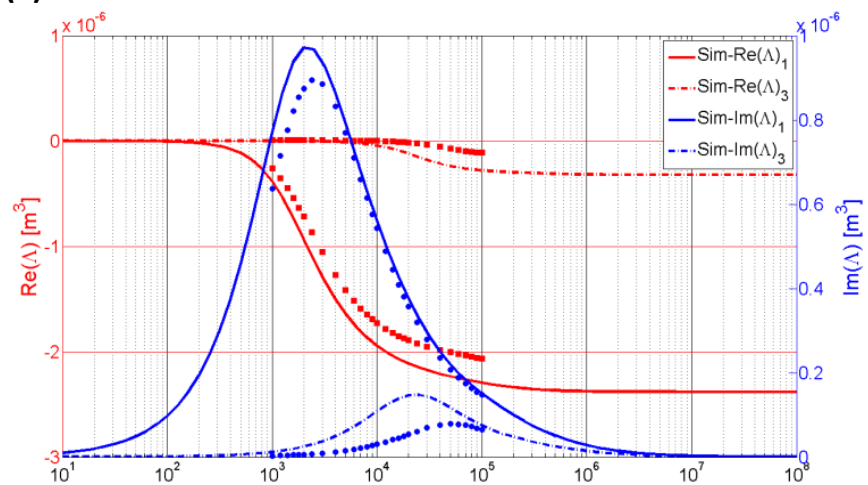

(c)

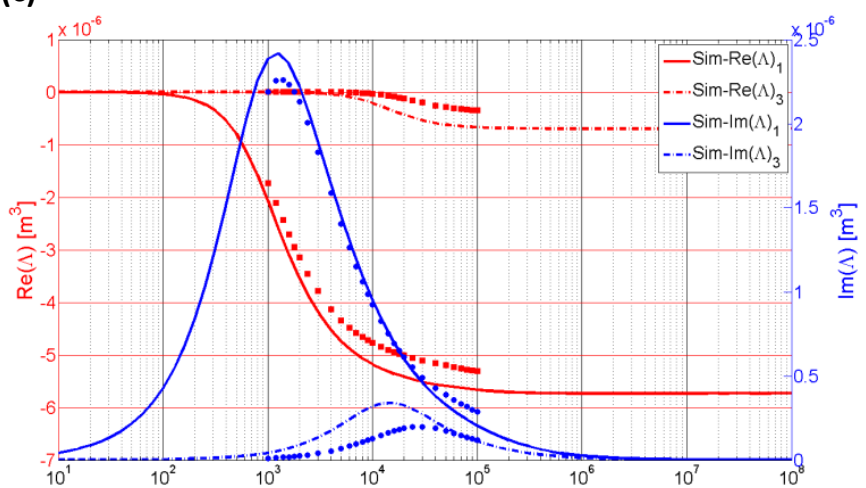

(e)

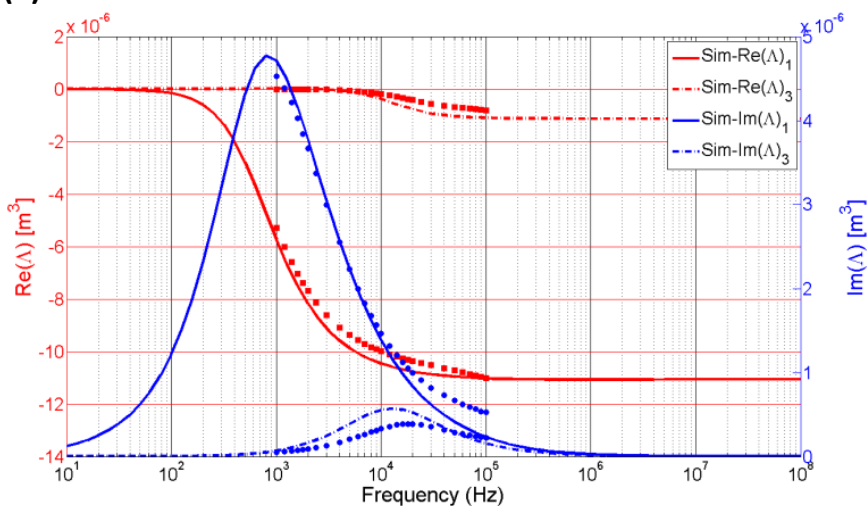

shows the calculated NRMSE values relative to the mean in the experimental data. The overall best fit between simulated and experimental data is for the disk modelled to a conductivity set to $2.72 \times 10^{6} \mathrm{~S} \mathrm{~m}^{-1}$ corresponding to $70-30$ $\mathrm{CuNi}$ binary alloy. This is particularly evident in the visually indiscernible differences between the experimental data points and simulated solid lines corresponding to the imaginary eigenvalue, $\Lambda_{1}$, as shown in Fig. 10(b).

(b)

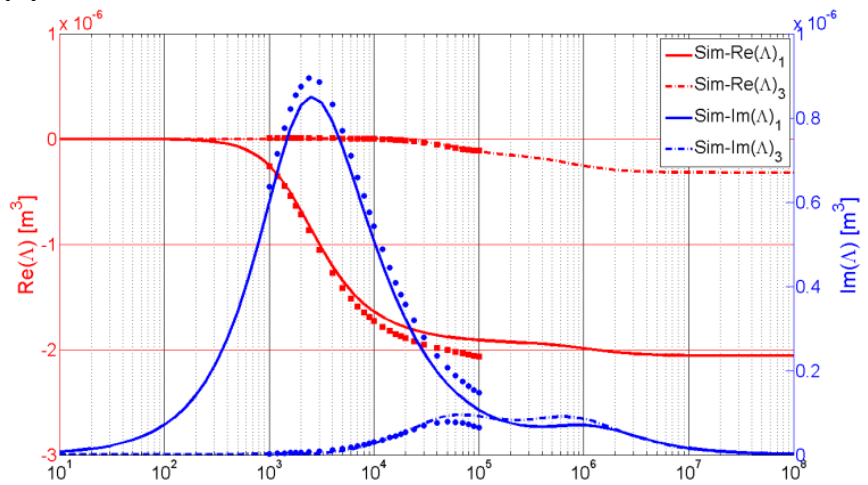

(d)

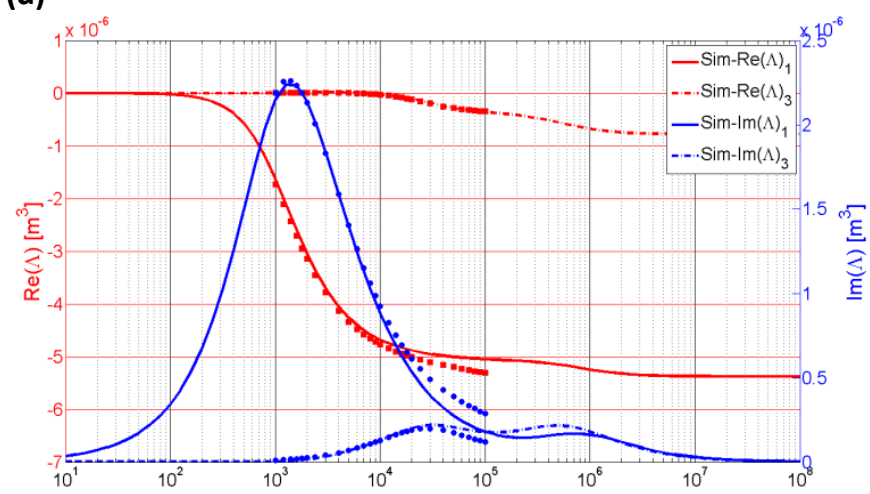

(f)

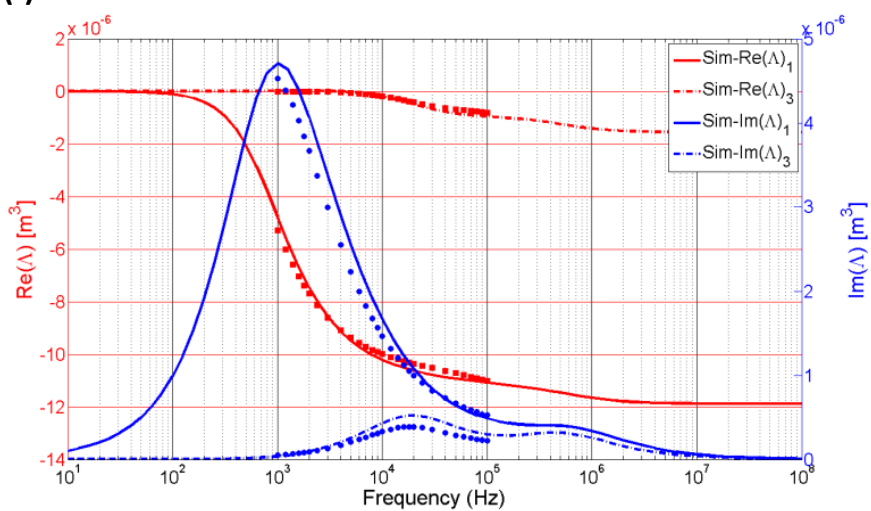

Fig. 11. US coins dime, quarter and half dollar all modelled with a core of $99-1 \mathrm{CuNi}\left(35.1 \times 10^{6} \mathrm{~S} / \mathrm{m}\right)$ without and with top and bottom cladding layers of $75-25 \mathrm{CuNi}\left(3.19 \times 10^{6} \mathrm{~S} / \mathrm{m}\right)$; (a)-(b) dime without and with $0.2 \mathrm{~mm}$ cladding, (c)-(d) quarter without and with $0.2 \mathrm{~mm}$ cladding, (e)-(f) half dollar without and with $0.3 \mathrm{~mm}$ cladding.

Table 7

NRMSE between the simulated and experimental values for the US dime, quarter dollar (QD) and half-dollar (HD) coins data of Fig. 11.

\begin{tabular}{|c|c|c|c|c|}
\hline & \multicolumn{2}{|c|}{ Real eigenvalues } & \multicolumn{2}{|c|}{ Imaginary eigenvalues } \\
\hline & $\Lambda_{1}$ & $\Lambda_{3}$ & $\Lambda_{1}$ & $\Lambda_{3}$ \\
\hline Dime (without cladding) & 0.127 & 1.028 & 0.103 & 0.667 \\
\hline Dime (0.2 $\mathrm{mm}$ cladding) & 0.068 & 0.251 & 0.083 & 0.261 \\
\hline QD (without cladding) & 0.083 & 0.793 & 0.067 & 0.568 \\
\hline QD $(0.2 \mathrm{~mm}$ cladding & 0.034 & 0.083 & 0.065 & 0.197 \\
\hline HD (without cladding) & 0.042 & 0.492 & 0.091 & 0.397 \\
\hline HD (0.3 mm cladding) & 0.026 & 0.261 & 0.111 & 0.275 \\
\hline
\end{tabular}


(a)

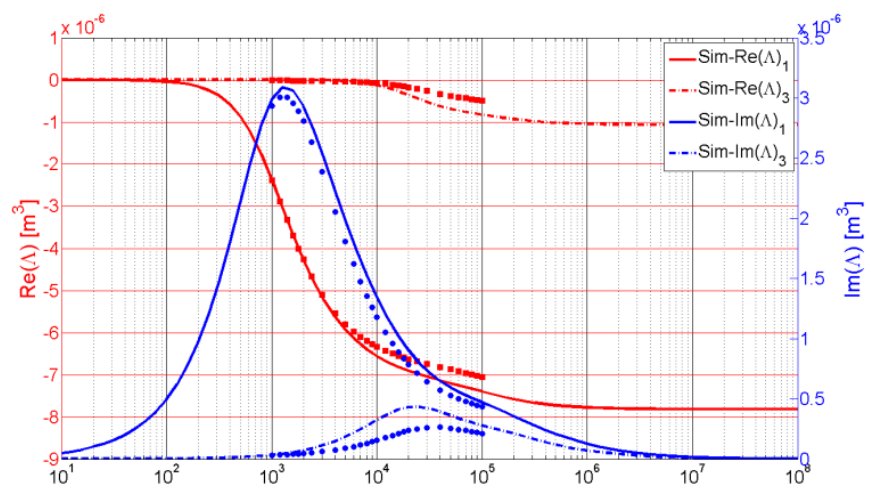

(c)

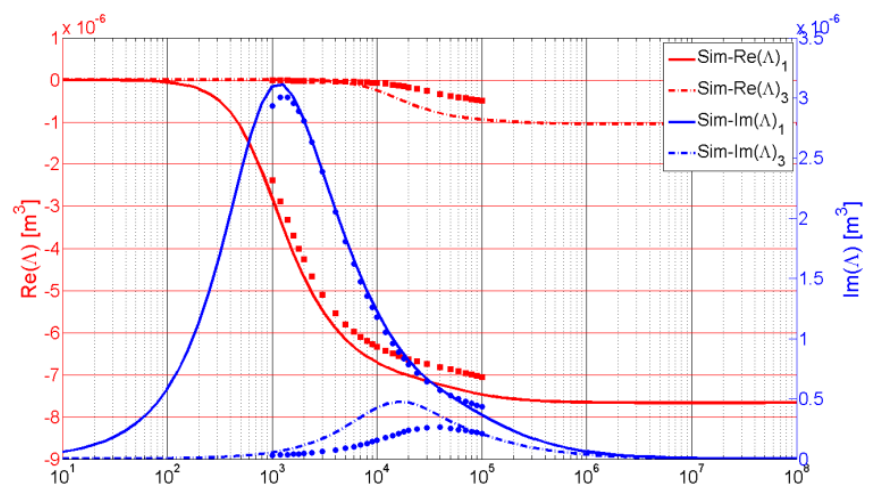

(e)

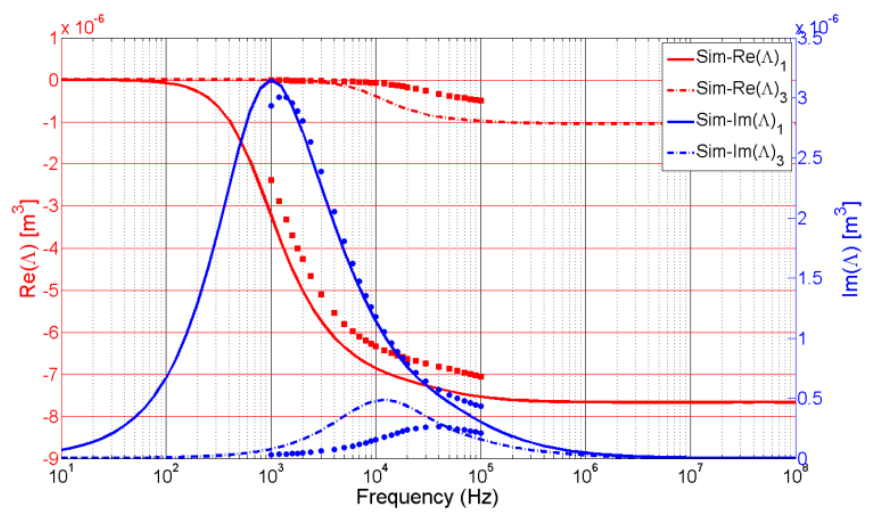

(b)

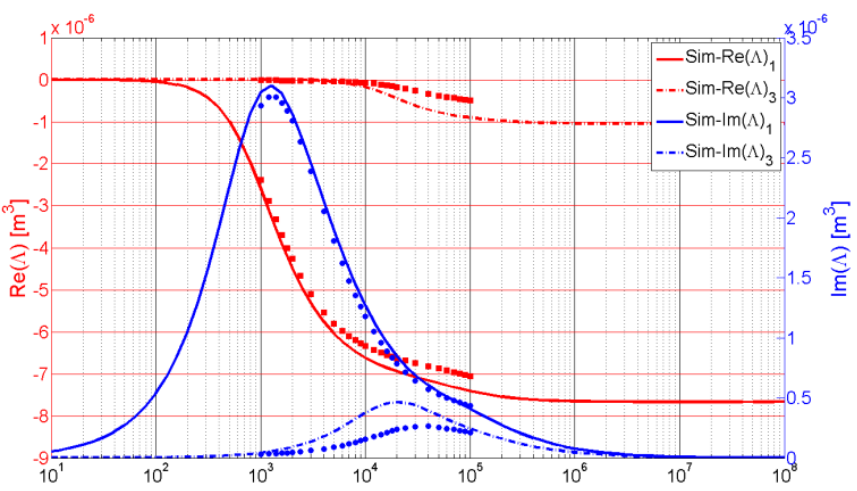

(d)

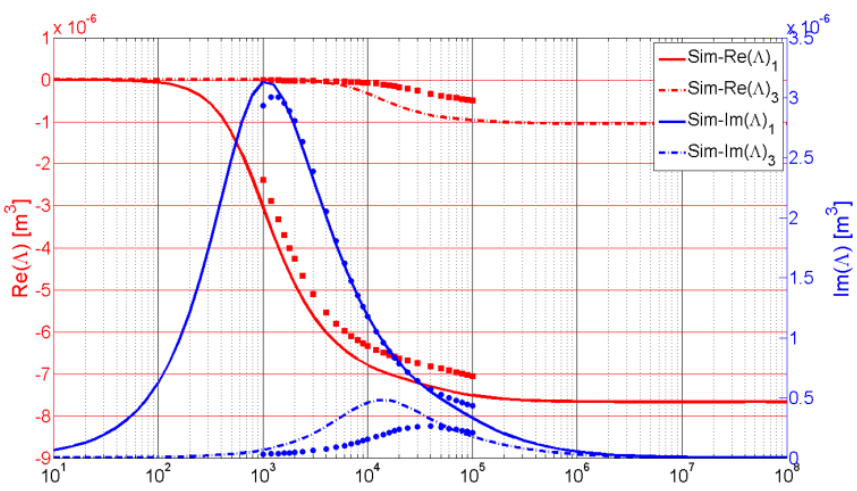

(f)

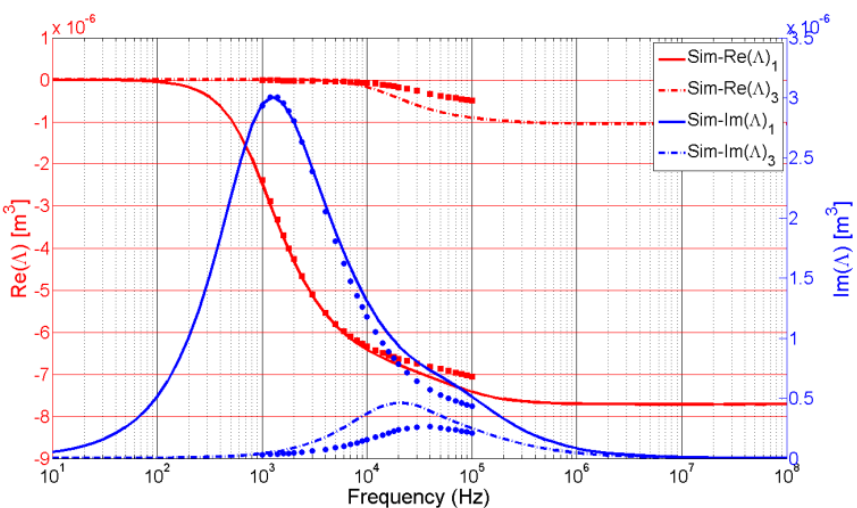

Fig. 12. US one dollar all modelled with a core of $99-1 \mathrm{CuNi}\left(35.1 \times 10^{6} \mathrm{~S} / \mathrm{m}\right)$; (a)-(e) with $0.4 \mathrm{~mm}$ top and bottom cladding layers of $20 \%$ to $60 \% \mathrm{Cu}$ conductivity in $10 \%$ incremental steps and (f); total wrap-around cladding with $30 \% \mathrm{Cu}$ conductivity $\left(17.4 \times 10^{6} \mathrm{~S} / \mathrm{m}\right)$.

Table 8

NRMSE of the differences between simulated and experimental values for the US dollar coin data of Fig. 12.

\begin{tabular}{|c|c|c|c|c|}
\hline & \multicolumn{2}{|c|}{ Real eigenvalues } & \multicolumn{2}{|c|}{ Imaginary eigenvalues } \\
\hline & $\Lambda_{1}$ & $\Lambda_{3}$ & $\Lambda_{1}$ & $\Lambda_{3}$ \\
\hline $20 \% \mathrm{Cu}$ & 0.039 & 0.657 & 0.078 & 0.480 \\
\hline $30 \% \mathrm{Cu}$ & 0.047 & 0.737 & 0.045 & 0.535 \\
\hline $40 \% \mathrm{Cu}$ & 0.065 & 0.779 & 0.034 & 0.583 \\
\hline $50 \% \mathrm{Cu}$ & 0.081 & 0.803 & 0.039 & 0.621 \\
\hline $60 \% \mathrm{Cu}$ & 0.094 & 0.818 & 0.058 & 0.653 \\
\hline $30 \% \mathrm{Cu}$ (total cladding) & 0.030 & 0.734 & 0.070 & 0.533 \\
\hline
\end{tabular}

Fig. 11 shows the measured and simulated derived eigenvalues of the spectroscopic tensor for the US coins dime, quarter and half dollar. As described in section 2.1, all these coins comprise of a roll-clad layer. The first left-hand side column of the figure compares experimental data with simulated results derived from simple models without using any cladding material, whereas the second column shows simulations using top and bottom cladding as described in Table 2. Modelling using solely top and bottom cladding for these coins was deemed a good representation of reality since 
even on newly circulated coins such as the quarter dollar the copper core is clearly visible along the edges of the coin. The eigenvalues for coins using cladding layers differ significantly compared with non-clad coins. For example, considering experimental measurements, and despite the limited number of data points at higher frequencies, such coins do not exhibit a truly symmetrical peak in the imaginary eigenvalue, $\Lambda_{3}$. This is due to the intrinsic nature of having a physical structure of different metals and alloys possessing different electromagnetic properties forming sandwich layers. Generally, the eigenvalues of Fig. 11 show better agreement for simulated data from models incorporating the cladding layers. This is particularly evident when looking at the shape, height and peak position of imaginary eigenvalue, $\Lambda_{3}$. For all cases of the dime, quarter and half dollar, the visual fit between experimental based eigenvalues and simulations from clad-type models is far better than for the non-clad models. This can be seen quantitatively in the lower NRMSE values shown in Table 7.

Fig. 12 shows the associated eigenvalue tensor data for the US dollar. In this case, experimental data is compared with models comprising of top and bottom cladding, and finally to a model using total wrap-around cladding which encompasses the edge of the coin. In reality, the cladding of the dollar itself is of manganese brass alloy as described in Table 1. In common with all brass alloys, the conductivity of the cladding is likely to be highly dependent on material composition since alloying of a pure metal significantly affects the electrical conductivity of the host metal, by causing lattice perturbations, modification of the electronic band structure and altering the lattice-vibrational spectrum [34]. For this reason, the conductivity of the cladding was treated as unknown, and initial top and bottom clad models set conductivities in the range of $20 \%$ to $60 \%$ of the IACS conductivity. As can be seen from Fig. 12(a-e), these simulations failed to give good agreement with experimental data for both real and imaginary components of eigenvalues, $\Lambda_{1}$ and $\Lambda_{3}$. However, the total wrap-around model using conductivity set to $30 \%$ of IACS conductivity yielded an improvement in fitting between experimental and simulated data. This is particularly true for the real and imaginary eigenvalues, $\Lambda_{1}$ as can be seen in Fig. 12(f). Although, agreement for real eigenvalue, $\Lambda_{3}$ is still relatively poor, the overall fit across all data using this model is much improved compared with the models using only top and bottom cladding. This is generally shown in the NRSME values shown in Table 8.
Considering all the coin data, there is a strong correlation between the magnitude of the eigenvalues and the size of the coins. In particular, smaller coins have smaller eigenvalues compared with larger coins which have larger eigenvalues. Additionally, the differences in magnitude between eigenvalues $\Lambda_{1}$ and $\Lambda_{3}$ very clearly show the relative size differences between the axial and traverse responses of the experimentally derived and simulated tensors. Namely, that the diameter of the coins are substantially greater than that of the thickness of the coins. However, the results suggest that the ratios of $\Lambda_{1}$ and $\Lambda_{3}$ do not directly correlate with the ratios of coin diameters to thicknesses. This is to be expected since the tensor information is not solely dependent upon the object's shape and size but also composition. This is also evident when looking at the peak frequencies in eigenvalue data shown in Table 9. Differences between the peak imaginary eigenvalues of the coins can be clearly seen. These peak positions are dependent on both composition and size of an individual coin. For example, as described in Table 1, the bulk composition of the dime, quarter and half dollar are identical. However, the sizes of the these coins are significantly different, increasing in size from the dime to quarter to half dollar with the half dollar being almost twice the diameter of the dime and five times its mass. As expected, the measured and simulated peak frequencies for the dime, quarter and half dollar decrease with increasing coin size. In the case of the cent, its composition is considerably different as it is a $\mathrm{Zn}$ based coin. The peak frequency in $\Lambda_{1}$ of the cent suggests that the overall conductivity of the cent is higher than that of the nickel but less than the dime. This is consistent with $\mathrm{Zn}$ being more conductive than $\mathrm{Ni}$ and the relatively high $25 \% \mathrm{Ni}$ composition of the CuNi based nickel coin results in the nickel having an overall lower conductivity compared with the cent. Additionally from Table 1, the composition of the dollar by weight is lower compared to that of the clad coins of the dime, quarter dollar and half dollar. All else being equal, this would suggest a relatively low peak frequency in $\Lambda_{1}$ and $\Lambda_{3}$ compared with e.g. the half dollar. However, the dollar is larger in size and weight compared with dime and quarter coins but is smaller than the half dollar. As a result the peak frequencies for the dollar appear to be similar to the quarter and lower than the dime. Here, the differentiating factor is the larger eigenvalue tensor magnitudes, indicating an object of greater size and lower conductivity.

Table 9

Peak frequencies of derived eigenvalues US coins.

\begin{tabular}{ccccc}
\hline & \multicolumn{2}{c}{$\begin{array}{c}\text { Peak frequency of imaginary } \\
\text { experimental eigenvalues }(\mathbf{k H z})\end{array}$} & \multicolumn{2}{c}{$\begin{array}{c}\text { Peak frequency of imaginary } \\
\text { simulated eigenvalues }\end{array}$} \\
& $\boldsymbol{\Lambda}_{\mathbf{1}}$ & $\boldsymbol{\Lambda}_{\mathbf{3}}$ & $\boldsymbol{\Lambda}_{\mathbf{1}}$ & $\boldsymbol{\Lambda}_{\mathbf{3}}$ \\
\hline One Cent & 5.0 & 50.0 & 4.0 & 39.8 \\
Nickel & 18.0 & above upper limit & 15.8 & 158.5 \\
Dime & 2.4 & 50.0 & 2.5 & 63.0 \\
Quarter & 1.4 & 30.0 & 1.3 & 31.6 \\
Half Dollar & 1.0 & 18.0 & 1.0 & 19.9 \\
Dollar & 1.2 & 30.0 & 1.3 & 20.0 \\
\hline
\end{tabular}


Generally the agreement between the FEM simulations and experimentally derived eignevalues for all the coins are far from ideal. This is primarily as a consequence of the modelling being unable to fully describe the true physical and electrical nature of a coin. The coining process is a complex multi-step process. In particular, the blanking and striking stages involve significant amounts of pressure which can be seen as a special case of cold working [35]. The cold working process typically reduces the conductivity of metals and alloys by the increased generation of crystalline dislocations $[36,37]$. Additionally, the processes of rolling and annealing used in coin manufacturing are known to have a significant effect on the electrical conductivity of copper based alloys [38]. Consequently, how all the processes used in coin manufacture impact on the electrical properties (e.g. conductivity) of a finished coin is unclear. For this reason, it is difficult to assign the true electrical properties of a coin within a FEM model. Despite this, the FEM data can give an additional understanding into the wider frequency spectroscopic nature of the tensor compared with the limited frequency range of the present experimental setup.

The presented results have significance in the area of coin discrimination and coin sorting. Most coin discrimination machines, work by testing physical properties of coins such as size, weight, thickness and materials using dimensioned slots, gates, optical sensors and electromagnets [39-41]. At very best, by use of electromagnetic sensors, some coin discriminators can only give relative permeability and conductivity information after acquisition of large sample sets necessary to train inbuilt algorithms to empirically determine the accept-reject threshold levels. This training method is generally both time-consuming and complicated. Moreover, such calibration procedures are not always sufficient and service engineers must sometimes be sent out to adjust the limits on particular machines. At best, such procedures still only give rise to a machine-specific relative signature of the coins of interest. However, if physical similarities exist between authentic coins and counterfeit coins, then some traditional coin testers can still fail to distinguish between the different coins. This is also true for two coins of different countries and values where physical parameters are not sufficient to distinguish accurately two similar coins. This was the case for the higher monetary value 2-Euro and the lower monetary value Turkish 1-Lira coins which were accepted in some slot machines due to inaccurate identification as reported by Khasmann et al. [42]. In theory, such scenarios could be avoided using the method described in this work which produces an absolute measurement of the tensor using magnetic induction spectroscopy. Further development of the experimental method presented e.g. extending over a wider frequency range, coil optimization and automated coin rotation could be used as a basic framework for advancing and contributing to the area of coin discrimination and sorting.

\section{Summary and Conclusions}

The eigenvalues of the absolute tensor response were measured for an uncirculated set of US coins. The presented results are encouraging as they strongly demonstrate the ability to characterize coins using an absolute tensor approach. The observations made on the eigenvalues of the measured coins show both a rich detail in the spectroscopic response and significant differences between different coin denominations. In all cases the agreement between the experimental and simulated data is reasonable. However, the results clearly bring out the limitations of comparing experimental tensor data with simplistic FEM models which, on the whole, are encouraging but fail to fully describe the spectroscopic nature of the tested coins. Nonetheless, even subtle differences due to relatively thin clad layers (e.g. less than 200 microns for the dime) are present within the data. These results strongly suggest that further research in applying the measurement of the absolute magnetic polarizability tensor could be highly valuable in the area of coin identification. For example, currency issuing authorities invest significant resources in the identification of counterfeit coins. In particular, the determination and cataloguing of adopted construction methods used by counterfeiters' is seen as crucial in developing new counter-measures against counterfeiting. It is proposed that the application of the spectroscopic tensor could be used not only to discriminate between authentic and counterfeit coins but also applied to the classification of counterfeit coins to compliment conventional metallurgical forensic analysis techniques presently used by currency issuing authorities such as the US Mint and the Royal Mint in the United Kingdom. In this way, the measurement of the spectroscopic tensor of known counterfeit coins may be able to be used as ultimately a more rapid catalogue classifier of previously identified adopted counterfeiting construction methods when assessed against counterfeit sample catalogues based on more resourceintensive forensic techniques such as microscopy and x-ray analysis.

\section{Acknowledgement}

This work was conducted as part of the research programme "SEMIS" (Scanning Electromagnetic Mine Inspection System) with funding from the charity Find A Better Way (www.findabetterway.org.uk) - Grant number 2011/002.

\section{References}

[1] Z. Yifei, Y. Wuliang, C. Ktistis, D. Butterworth and A. J. Peyton, "On the Low-Frequency Electromagnetic Responses of In-Line Metal Detectors to Metal Contaminants", Instrumentation and Measurement, IEEE Transactions on, vol. 63, pp. 3181-3189, 2014.

[2] M. D. O’Toole, L. A. Marsh, J. L. Davidson, Y. M. Tan, D. W. Armitage and A. J. Peyton, "Non-contact multifrequency induction spectroscopy system for industrial-scale bio-impedance measurement", Measurement Science and Technology, vol. 26, p. 035102, 2015.

[3] S. J. Norton and I. J. Won, "Identification of buried unexploded ordnance from broadband electromagnetic induction data", Geoscience and Remote Sensing, IEEE Transactions on, vol. 39, pp. 2253-2261, 2001.

[4] D. J. Daniels, P. Curtis, R. Amin, N. Hunt, "MINEHOUND production development", Proc. SPIE 5794, Detection and Remediation Technologies for Mines and Minelike Targets X, 488 (July 08, 2005); doi:10.1117/12.601888.

[5] R. C. Doheny, S. Burke, R. Cresci, P. Ngan, and R. Walls, "Handheld standoff mine detection system (HSTAMIDS) field 
evaluation in Thailand", Proc. SPIE 5794, Detection and Remediation Technologies for Mines and Minelike Targets X, 889 (July 08, 2005); doi:10.1117/12.617920.

[6] M. Sato, K. Takahashi, "Hand-held dual-sensor ALIS and its evaluation tests", Proc. SPIE 6953, Detection and Sensing of Mines, Explosive Objects, and Obscured Targets XIII, 695311 (April 14, 2008); doi:10.1117/12.777236.

[7] H. Griffiths, "Magnetic induction tomography", in Electrical Impedance Tomography: Methods, History and Applications, D. S. Holder, Ed., IOP Publishing, 2005, 213-238.

[8] M. Zolgharni, P. D. Ledger, D. W. Armitage, D. Holder, and H. Griffiths, "Imaging cerebral haemorrhage with magnetic induction tomography: Numerical modelling," Physiol. Meas., vol. 30, no. 6, pp. 187-200, 2009.

[9] M. Soleimani, W. R. B. Lionheart and A. J. Peyton, "Image reconstruction for high-contrast conductivity imaging in mutual induction tomography for industrial applications", IEEE Trans. Instrum. Meas., vol. 56, no. 5, pp. 2024-2032, Oct. 2007.

[10] C. Camerini, R. Sacramento, M. C. Areiza, et al., "Eddy current techniques for super duplex stainless steel characterization", J. Magn. Magn. Mater. 338 (2015) 96-100.

[11] S. Kahrobaee and M. Kashefi, "Electromagnetic nondestructive evaluation of tempering process in AISI D2 steel”, J. Magn. Magn. Mater. 382 (2015) 359-365.

[12] J. García-Martín, J. Gómez-Gil and Vázquez-Sánchez, "Nondestructive techniques based on eddy current testing", Sensors vol. 11, 2525-2565, 2011, doi: 10.3390/s110302525.

[13] P. Gaydecki, I. Silva, B. T. Fernandes, and Z. Z. Yu, "A portable inductive scanning system for imaging steelreinforcing bars embedded within concrete", Sens. Actuators A, Phys., vol. 84, nos. 1-2, pp. 25-32, Aug. 2000.

[14] J. P. Fernandez, B. E. Barrowes, T. M. Grzegorczyk, N. Lhomme, K. O'Neill and F. Shubitidze, "A Man-Portable Vector Sensor for Identification of Unexploded Ordnance", Sensors Journal, IEEE, vol. 11, pp. 2542-2555, 2011.

[15] J. Makkonen, L. A. Marsh, J. Vihonen, A. Järvi, D. W. Armitage, et al., "KNN classification of metallic targets using the magnetic polarizability tensor," Measurement Science and Technology, vol. 25, p. 055105, 2014.

[16] C. R. Gagg and P. R. Lewis, 2007. "Counterfeit coin of the realm - Review and case study analysis", Engineering Failure Analysis, Vol. 14, pp. 1144-1152.

[17] Royal Mint. [Online] Available at: http://www.royalmint.com/discover/uk-coins/counterfeit-onepound-coins

[18] M. Hida, H. Sato, H. Suguwara and T. Mitsui "Classification of counterfeit coins using multivariate analysis with X-ray diffraction and X-ray fluorescence methods", Forensic Science International, vol. 115, pp. 129-134, 2014.

[19] M. Hida, T. Mitsui and Y. Minami "Forensic investigation of counterfeit coins", Forensic Science International, vol. 89, pp. 21-26, 1997.

[20] U. S. Mint. (July 2015), Coin Specification. [Online] Available at: http://www.usmint.gov/about_the_mint/?action= coin_specifications

[21] “Alternative Metals Study Phase II Technical Report", 2014 Biennial Report by US Mint to US Congress [Online] Available at: https://www.usmint.gov/about_the_mint/ ?action=specialreports

[22] P. D. Ledger and W. R. B. Lionheart, "Understanding the Magnetic Polarizability Tensor”, IEEE Trans. Magn., vol. 52, no. 5, May 2016, doi: 10.1109/TMAG.2015.2507169.

[23] H. Ammari and H. Kang, Polarization and Moment Tensors: With Applications to Inverse Problems and Effective Medium Theory. New York, NY, USA: Springer, 2007.

[24] H. Ammari, M. S. Vogelius, and D. Volkov, "Asymptotic formulas for perturbations in the electromagnetic fields due to the presence of inhomogeneities of small diameter II. The full
Maxwell equations," J. Math. Pures Appl., vol. 80, no. 8, pp. 769-814, Oct. 2001.

[25] P. D. Ledger and W. R. B. Lionheart, "The perturbation of electromagnetic fields at distances that are large compared with the object's size", IMA J. Appl. Math., vol. 80, no. 3, pp. 865-892, 2015.

[26] Y. Das, J. E. McFee, J. Toews and G. C. Stuart, "Analysis of an Electromagnetic Induction Detector For Real-Time Location of Buried Objects", Geoscience and Remote Sensing, IEEE Transactions on, vol. 38, pp. 278-288, 1990.

[27] Y. Zhang, L. Collins, H. Yu, C. Baum and L. Carin, "Sensing of un-exploded ordnance with magnetometer and induction data: Theory and signal processing", IEEE Trans. Geosci. Remote Sens., vol. 41, no. 5, pp. 1005-1015, May 2003

[28] T. M. Grzegorczyk, B. E. Barrowes, F. Shubitidze, J. P. Fernandez and K. O'Neill, "Simultaneous Identification of Multiple Unexploded Ordnance Using Electromagnetic Induction Sensors", Geoscience and Remote Sensing, IEEE Transactions on, vol. 49, pp. 2507-2517, 2011.

[29] L. A. Marsh, C. Ktistis, A. Järvi, D. W. Armitage and A. J. Peyton, "Three-dimensional object location and inversion of the magnetic polarizability tensor at a single frequency using a walk-through metal detector", Measurement Science and Technology, vol. 24, p. 045102, 2013.

[30] T. H. Bell, B. J. Barrow and J. T. Miller, "Subsurface Discrimination Using Electromagnetic Induction Sensors", IEEE Transactions on Geoscience and Remote Sensing, vol. 39, pp. 1286-1293, June 2001.

[31] P. P. Silvester and D. Omeragic, "Sensitivity maps for metal detector design", IEEE Trans. Geosci. Remote Sens., vol. 34, no. 3, pp. 788-792, May 1996.

[32] O. Rehim, J. L. Davidson, L. A. Marsh, M. D. O'Toole and A.J. Peyton, "Magnetic polarizability tensor spectroscopy for low metal anti-personnel mine surrogates", IEEE Sensors Journal, vol. 16(10), pp. 3775-3783, 2016.

[33] O. A. A. Rehim, J. L. Davidson, L. A. Marsh, M. D. O'Toole, D. W. Armitage, and A. J. Peyton, "Measurement system for determining the magnetic polarizability tensor of small metal targets", in Sensors Applications Symposium (SAS) 2015, IEEE, 2015, pp. 1-5

[34] C. Y. Ho, M. W. Ackerman, K. Y. Wu, T. N. Havill, R. H. Bogaard, R. A. Matula, et al., "Electrical Resistivity of Ten Selected Binary Alloy Systems", Journal of Physical and Chemical Reference Data, vol. 12, pp. 183-322, 1983.

[35] F. Delamare and P. Montimitonnet, "A mechanical analysis of coin striking", J. of Mech. Work. Technol., vol. 10, 253, 1984.

[36] Cem S. Çetinarslan, 2009. "Effect on cold plastic deformation on electrical conductivity of various metals", Materials and Design, Vol. 30, pp. 671-673.

[37] S. Nagarjuna, K. Balasubramanian and D. S. Sarma, "Effect of prior cold work on mechanical properties, electrical conductivity and microstructure of aged $\mathrm{Cu}-\mathrm{Ti}$ alloys", J. Materials Science, Vol. 34, (1999) pp. 2929-2942.

[38] Sh. Raygan, H. Ehsanian Mofrad, M. Pourabdoli and F. K. Ahadi, 2011. "Effect of rolling and annealing process on the hardness and electrical conductivity values of $\mathrm{Cu}-13.5 \% \mathrm{Mn}-4 \% \mathrm{Ni}$ alloy", Journal of Materials Processing Technology, Vol. 211, pp. 1810-1816.

[39] A. Carlosena, A. J. López-Martin, F. Arizti et al., 2007, "Sensing in Coin Discriminators", Proceedings of Conf. $2^{\text {nd }}$ IEEE Sensors Applications Symposium, San Diego, CA, USA.

[40] E. Hibari and J. Arikawa, 2001. Coin discriminating apparatus, European Patent EP1077434.

[41] A. Ondodera and M. Sugata, 2002. Coin discrimination method and device. United States Patent US2002005329.

[42] A. Khashmann, B. Sekeroglu and K. Dimililer, 2006. "ICIS: A novel coin identification system", In: Proceedings of Intl. Conf. on Intelligent Computing (ICIC), Kunming, China. 